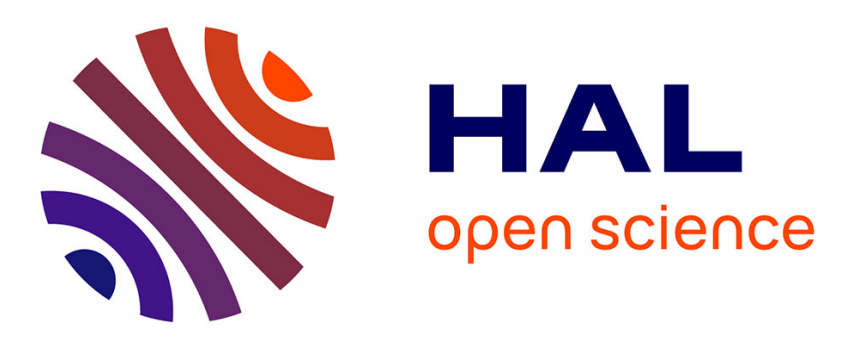

\title{
3D damage micromechanisms in polyamide 6 ahead of a severe notch studied by in situ synchrotron laminography
}

Yin Cheng, Lucien Laiarinandrasana, Lukas Helfen, Henry Proudhon, Olga Klinkova, Tilo Baumbach, Thilo F. Morgeneyer

\section{To cite this version:}

Yin Cheng, Lucien Laiarinandrasana, Lukas Helfen, Henry Proudhon, Olga Klinkova, et al.. 3D damage micromechanisms in polyamide 6 ahead of a severe notch studied by in situ synchrotron laminography. Macromolecular Chemistry and Physics, 2016, 217, pp.701-715. 10.1002/macp.201500316. hal-01402600

\section{HAL Id: hal-01402600 \\ https://hal.science/hal-01402600}

Submitted on 24 Nov 2016

HAL is a multi-disciplinary open access archive for the deposit and dissemination of scientific research documents, whether they are published or not. The documents may come from teaching and research institutions in France or abroad, or from public or private research centers.
L'archive ouverte pluridisciplinaire HAL, est destinée au dépôt et à la diffusion de documents scientifiques de niveau recherche, publiés ou non, émanant des établissements d'enseignement et de recherche français ou étrangers, des laboratoires publics ou privés. 


\title{
3D damage micromechanisms in polyamide 6 ahead of a severe notch studied by in situ synchrotron laminography
}

\author{
Y. Cheng, ${ }^{,+, \dagger}$ L. Laiarinandrasana, ${ }^{\dagger}$ L. Helfen,,$+{ }^{\dagger}$ H. Proudhon, ${ }^{\dagger} \mathrm{O}$. Klinkova, ${ }^{\dagger}$ \\ T. Baumbach, ${ }^{\ddagger}$ and T. F. Morgeneyer, ${ }^{*} \dagger$
}

Centre des Matériaux, MINES ParisTech, PSL Research University, CNRS UMR 7633, BP 87 Evry Cedex, France, Laboratory for Applications of Synchrotron Radiation (LAS), Karlsruhe Institute of Technology (KIT), D-76049 Karlsruhe, Germany, and European Synchrotron Radiation Facility (ESRF), BP 220, F-38043 Grenoble Cedex, France

E-mail: yin.cheng@gmx.com; thilo.morgeneyer@mines-paristech.fr Phone: +33160 763061. Fax: +33160763150

\section{Abstract}

Micro-damage mechanisms in a semicrystalline PolyAmide 6 polymer were characterized by in situ synchrotron radiation computed laminography (SRCL) using compact-tension like specimens with a notch root radius of $0.25 \mathrm{~mm}$. SRCL allows the quantification of cavity nucleation, growth and coalescence in flat $2 \mathrm{~mm}$ thick notched specimens with a micrometer resolution in 3D (under conditions of severe stress triaxiality) during the in situ loading. The maximum damage occurred at mid-thickness and was located at a small distance $\sim 200 \mu \mathrm{m}$ from the notch root. It is shown that damage was distributed in distinct zones, that could be linked to different stress triaxiality states. Penny shaped cracks were found after some loadings. Their diameters were a function of the distance to the notch root: In a layer of

\footnotetext{
*To whom correspondence should be addressed

${ }^{\dagger}$ Centre des Matériaux, MINES ParisTech, PSL Research University, CNRS UMR 7633, BP 87 Evry Cedex, France

${ }^{\ddagger}$ Laboratory for Applications of Synchrotron Radiation (LAS), Karlsruhe Institute of Technology (KIT), D-76049 Karlsruhe, Germany

`European Synchrotron Radiation Facility (ESRF), BP 220, F-38043 Grenoble Cedex, France
}

about $33 \mu \mathrm{m}$ no damage was found. In the adjacent $128 \mu \mathrm{m}$ layer penny-shaped cracks were found with diameters of the order of average spherulite sizes $(4-6 \mu \mathrm{m})$. In the next region 30-45 $\mu \mathrm{m}$ long cracks were found corresponding to several average spherulite diameters. During propagation, tunnel-like cracks formed ahead of the main crack. Finally, crack initiation location was found to be largely dependent on the roughness of the machined notch surface by comparing two samples with the same loading conditions.

\section{Introduction}

Semicrystalline polymers are frequently employed in engineering components that are subjected to thermomechanical loadings, therefore considerable efforts have been made in the past few decades to understand their mechanical behaviour in terms of deformation and damage mechanisms in connection with their microstructural organization. Under tensile drawing, cavitation or crazing $^{1-12}$ have been identified as major damage processes in many semicrystalline polymers ${ }^{13}$ including polyamide 6 (PA6).

Various techniques have been exploited to ob- 
serve such phenomena over a wide range of length scales. Many mechanisms of deformation can be revealed by electron microscopes including SEM and TEM, which reveal damage features with sizes from nanometers to a few micrometer. In the literature, Galeski and coauthors presented direct TEM evidence for cavitation, chemical damage and/or density reduction in localized regions of the microstructure of bulk spherulitic nylon 6 under plastic deformation. They proposed a physical picture suggesting possible complex deformation processes in a spherulite due to uniaxial tension. ${ }^{14}$ Aboulfaraj et al. differentiated the $\alpha$ - and $\beta$-spherulites in polypropylene (PP) by SEM after appropriate etching ${ }^{15}$ and further revealed specific responses with both types of spherulites with respect to uniaxial tensile and simple shear deformation. ${ }^{16}$ Dijkstra et al. ${ }^{17}$ proposed a failure transition model from yielding to crazing based on their SEM observations of PP specimens subjected to varying strain rates. Henning et al. ${ }^{18}$ compared the micromechanical behaviours between the $\alpha$ - and $\beta$-modified isotactic PP. At room temperature $\left(23{ }^{\circ} \mathrm{C}\right)$ the microvoids were visible in the polar region of the $\alpha$-iPP, whilst in the $\beta$-iPP intensive microvoid formation took place in the whole volume. At $-40{ }^{\circ} \mathrm{C}$ only a few but long and coarse crazes were found for the $\alpha$-form, however much smaller, thin and numerous crazes were typical for the $\beta$-form. The measured enhanced toughness of the $\beta$-iPP was then linked to these micromechanisms by the authors and attributed to the lamellar nanostructure arrangement of $\beta$-spherulite. However, the required sample preparations (i.e. chemical etching) constrained both methods to either ultra-thin (100-500 nm) films or interrupted and unloaded (usually with deformed samples) investigations. By applying atomic force microscopy (AFM), Ferreiro et al. ${ }^{19,20}$ showed the competitive nanoscopic observation (down to the lamellar scale) of shear band deformation of a relatively thick $(80 \mu \mathrm{m})$ PA6 film under uniaxial tension at yield. The authors demonstrated that below $160{ }^{\circ} \mathrm{C}$ shear bands which intersect at an angle of $104^{\circ}$ within the amorphous interlamellar phase of the spherulites govern the plastic deformation in this plane stress state.
Thomas et $a l .{ }^{21,22}$ further applied in situ AFM, they captured craze initiation and growth in several $100 \mu \mathrm{m}$ thick polybutene (PB) films with different spherulite sizes and concluded the structural size dependence of plastic processes in PB. At a similar length scale, small-angle $\mathrm{X}$-ray scattering (SAXS) and wide-angle Xray scattering (WAXS) have also been broadly utilized. They allow for an averaged in situ investigation of even thicker ( $\mathrm{mm}$ size) samples at the 1-100 nm scale taking advantage of high energy and short wavelengths of X-rays. Castagnet et $a l .{ }^{23}$ studied $\alpha$ polyvinylidene fluoride (PVDF) by volume strain measurements, WAXS and SAXS experiments. They showed that cavitation predominated in equatorial intraspherulitic amorphous layers before yielding, and futher nucleated in other areas for higher strains. This process dominated the deformation in PVDF deformation over crystallite fragmentation. Pawlak and co-authors ${ }^{24-26}$ characterized cavity evolution during the tensile deformation of PP. Amongst their findings was that the cavities initiated in the amorphous phase in the equatorial part of spherulites. Nanovoids as well as microvoids changed their orientation from elongated perpendicular to being parallel to the deformation axis, i.e. the damage in the polar fans of spherulites. They are responsible for the whitening of samples. Assisted by SEM, the "polar fan" damage in deformed sections has also been observed.

Since SAXS is an indirect method to assess damage features, synchrotron X-ray microtomography ( $\mathrm{SR} \mu \mathrm{CT}$ ) has been recently explored by several researchers in order to better understand the deformation induced whitening at the mesoscale level (from hundreds of nanometers to a few micrometers) as well as in a nondestructive way as compared to SEM. Laiarinandrasana et al. ${ }^{27}$ made the first attempt on smooth round bar semicrystalline PA6 specimens after interrupted tensile tests. With a voxel size of $0.7 \mu \mathrm{m}$, they imaged 3D bulk volumes of the necked region and revealed pennyshaped crazes and void columnar-structures that aligned along the tensile axis. Further studies were conducted on notched round bar specimens under interrupted tests accompanied 
by image analysis ${ }^{28}$ and reinforced the conclusion that the multiaxial stress state produced by the notch increased the size of damage features and defined the distribution of voids. Similar $\mathrm{SR} \mu \mathrm{CT}$ measurements have been described by N. Brusselle-Dupend et al. ${ }^{29}$ and Rosenberg et al..$^{30}$ on PVDF.

Blaise et $a l^{31}$ who performed postmortem $\mathrm{SR} \mu \mathrm{CT}$ examinations coupled with 2D FFT analyses on a predeformed high density polyethylene (HDPE), suggesting that the commonly admitted crazing mechanism could not account for the whitening of such "noncavitating" materials upon necking, ${ }^{32}$ but could result from the crystalline transformation. Soon after, a comparable technique at the same spatial range called incoherent polarized steady-light transport (IPSLT) was used by those authors and confirmed their $\mathrm{SR} \mu \mathrm{CT}$ results. ${ }^{33}$ Further work followed by Farge et $a l .,{ }^{34}$ who combined both IPSLT and postmortem SR $\mu \mathrm{CT}$ on highly cavitating $\mathrm{PP}$, enriched Blaise's result that the origin of whitening may differ between different semicrystalline polymers. In their study, "zebra patterns" and "cigar shape" array of holes were observed that were similar to the observation in PA6 by Laiarinandrasana et al. They speculated that the whitening phenomenon in PP was due to confined groups of nanovoids in the equatorial disks of spherulites, which however could not be detected by the IPSLT and SR $\mu \mathrm{CT}$. Very recently, Morgeneyer et al. ${ }^{35}$ applied the synchrotron nano-holotomography ${ }^{36,37}$ to a polymer showing promising results of the nanovoid morphology and distribution in a deformed HDPE with a voxel size of $59.7 \mathrm{~nm}$. Nanovoids were found that were elongated in the tensile direction. Their attempt may answer the question of Blaise and Farge, and fill the gap between SAXS and IPSLT/SR $\mu \mathrm{CT}$. It should also be noted that IPSLT is an averaged volume measurement. Apparently all these tools assessing damage at different length scales can effectively complement each other. In a recent paper, Farge et al..$^{38}$ combined SAXS, in situ IPSLT, postmortem $\mathrm{SR} \mu \mathrm{CT}$ and $3 \mathrm{D}$ digital image correlation covering a multiscale study of the deformation mechanisms in a semicrys- talline HDPE, and emphasized the impact of microscale organizations on the macroscale behaviours.

Despite tremendous efforts paid to understand the cavitation, ${ }^{13}$ little information can be found concerning the crack initiation and propagation mechanisms in polymers, ${ }^{39-43}$ which is highly important for mechanical modeling. Narisawa and Ishikawa ${ }^{44,45}$ carried out numerous polarized optical micrograph inspections on various deformed semicrystalline thermoplastics. However, the inner microstructure evolution was inaccessible and little evidence was provided on the proposed crack propagation criteria. In the present study, thanks to the synchrotron computed laminography $(\mathrm{SR} \mu \mathrm{CL}),{ }^{46-49}$ it has been possible to trace the volumetric micro-crack initiation and propagation in a $2 \mathrm{~mm}$ thick notched PA6 laminate under severe triaxial stresses. SR $\mu$ CL is a nondestructive 3D X-ray imaging technique that allows for the assessment of the inner microstructure of a plate-like object. It overcomes the general limitation in $\mu \mathrm{CT}$ measurement for which small cylindrical or dog-bone-shaped specimens are used because these small specimens are sometimes still very different from standard mechanical tests and their plastic zones at the notch tips can be possibly larger than the specimen thickness: SR $\mu$ CL fulfills the most realistic engineering boundary conditions and particularly when coupled with in situ tests. The observed fracture mechanisms will be described and a comparison made between these findings and damage features in less deformed materials from previous $\mathrm{SR} \mu \mathrm{CT}$ observations.

In this study, two in situ SR $\mu \mathrm{CL}$ experiments were conducted on two PA6 specimens. The first experiment was conducted at the European Synchrotron Radiation Facility (ESRF), Grenoble, France. Local laminography ${ }^{50}$ was applied in which the $2 \mathrm{~mm}$ specimen thickness exceeded the effective field of view (FOV $\sim 1.4 \mathrm{~mm}$ ) of the detector. There was a smooth defect-free notch surface (Figure 2a), however a limited number of loading steps were recorded during the measurement. For this reason, the same experiment was repeated at the ANKA light source, Karlsruhe, Germany, in order to follow 
more load increments as well as to examine the entire specimen thickness in the FOV. However, a notch roughness defect was introduced, due to a poor machining, in the latter experiment (Figure 2b) which turned out to be an advantage because it brought new information and could be seen as having an impact on the failure mechanisms.

\section{Experimental Section}

\section{Material}

The PolyAmide 6 (PA6) under study was a semicrystalline polymer provided by Angst \& Pfister as $610 \mathrm{~mm} \times 1230 \mathrm{~mm}$ flow moulded plates $10 \mathrm{~mm}$ in thickness. Its physicochemical properties have been published elsewhere ${ }^{27,28}$ (crystallinity was 43\%, Supporting Information Table S1). To reveal its spherulitic microstructure, examinations by SEM and optical microscope of the samples can be found in Refs. $27,51,52$. The average spherulite diameter was $\sim 5 \mu \mathrm{m}$ from SEM image analysis.

The plate was cut into $40 \times 50 \mathrm{~mm}^{2}$ specimens and further machined symmetrically in the center to a thickness of $2 \mathrm{~mm}$ in order to guarantee sufficient X-ray transmission in the beam. ${ }^{48,53}$ The notch was machined close to a radius of $0.25 \mathrm{~mm}$ by wire saw cutting in the case of a defective notch, and by a milling tool in the case of a defect-free notch. The loading direction, the crack propagation direction (notch direction) and the short transverse direction (through-thickness direction) are referenced to the letters L, P and S respectively as indicated in Figure 1. The loading test was performed in the L-P configuration.

\section{Mechanical Test}

The geometry of the flat notched specimen is shown in Figure 1. To ensure the reproducibility, several mechanical pre-tests have been performed before conducting the synchrotron experiment, and also one in situ x-ray test was carried out on a $1 \mathrm{~mm}$ thick specimen. Both cases produced the same trend as the results reported in this study. Mechanical tests were carried out at room temperature $\left(20^{\circ} \mathrm{C}\right)$ and $50 \%$ relative humidity $(\mathrm{RH})$. The loading was achieved via a 2 -screw displacement controlled wedging rig that imposed the specimen crack mouth opening displacement (CMOD) without measuring the load level. Stepwise loading was applied between different laminography scans. Each scan began after waiting 5 min, ensuring that the short-term stress relaxation and the material's viscoplasticity did not perturb the image quality. The applied CMOD was $0.7 \mathrm{~mm}$ and $1 \mathrm{~mm}$ per turn on the defective notch and defect-free notch, respectively. An anti-buckling device (Supporting Information Figure S1) was mounted around the specimen, leaving a window for the synchrotron X-ray laminography close to the notch so as to prevent the thin sheet from buckling in the compressive zone as well as out-of-plane motion. The scanned region of interest (ROI) was close to the notch and moved along with the propagating crack tip to image the damaged material ahead of the notch tip.

\section{Micrometer In Situ SRCL Imaging}

$\mathrm{SR} \mu \mathrm{CT}$ is a well established tool for 3D imaging of one-dimensionally extended objects (e.g. cylindrical samples) that stay in the field of view of the detector system during rotation. In contrast, $\mathrm{SR} \mu \mathrm{CL}$ is representing a scheme which allows 3D imaging without destruction of the specimen the lateral dimensions of which largely exceed the effective FOV (laterally extended i.e. plate-like specimens). For laminography, the rotation axis of the specimen is inclined at an angle of $\theta<90^{\circ}$ with respect to the incident $\mathrm{X}$-ray beam direction, while in the case of CT $\theta=90^{\circ}$ (Supporting Information Figure S2).

Imaging of the defect-free notch was performed on KIT's laminography instrument installed at beamline ID19 ${ }^{54}$ of the European Synchrotron Radiation Facility (ESRF, Grenoble, France). An inclination angle of the specimen rotation axis of $25^{\circ}$ with respect to the beam normal $\left(\theta \approx 65^{\circ}\right)$ was chosen as well as a monochromatic beam of $25 \mathrm{keV}$ X-ray energy. Volumes were reconstructed from 1500 

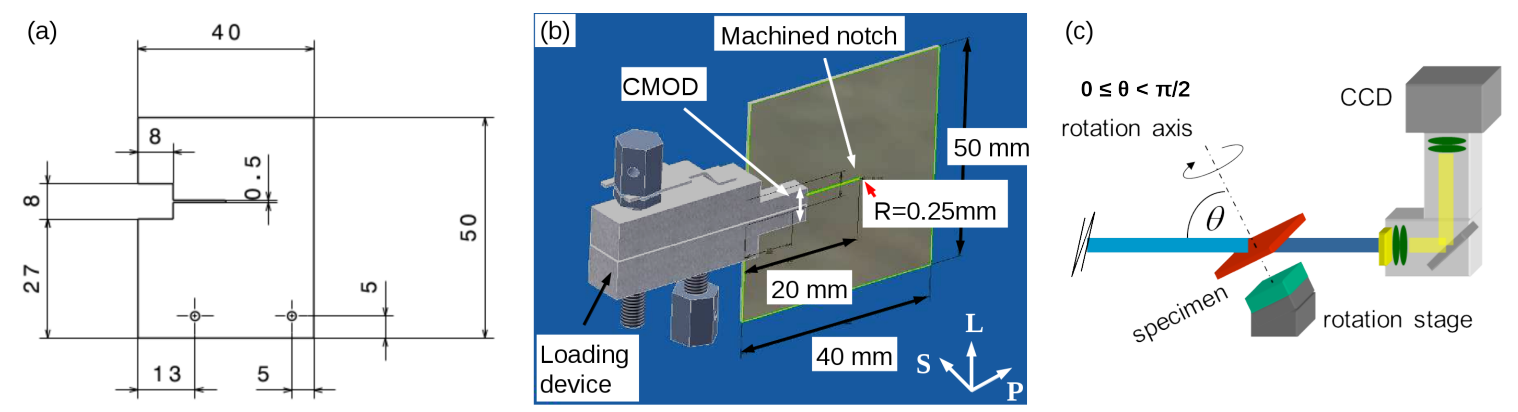

Figure 1: (a) Compact-tension like specimen geometry. (b) In situ loading device and the 2 $\mathrm{mm}$ thick notched specimen. The notch radius is $\sim 0.25 \mathrm{~mm}$ (the anti-buckling device is not shown here). L: loading direction, P: crack propagation direction, S: short transverse direction. (c) Schematic of 3D synchrotron computed laminography for imaging of regions of interest inside plate-like specimens.

angularly equidistant radiographs, the exposure time of each projection was $50 \mathrm{~ms}$. The scanned region was $\sim(1.5 \mathrm{~mm})^{3}$ in volume with a voxel size of $0.75 \mu \mathrm{m}$. The minimum specimen to detector distance was $70 \mathrm{~mm}$ leading to relatively strong edge enhancement ${ }^{55}$ due to phase contrast. 3D cross-sectional slices of the imaged specimen normal to the rotation axis have been reconstructed from the $2 \mathrm{D}$ projections using a filtered-backprojection algorithm. ${ }^{56}$ The final reconstructed volumes have a size of 2040 $\times 2040 \times 2040$ voxels.

Imaging of the defective notch was performed at the TopoTomo beamline ${ }^{57}$ of the ANKA light source (Karlsruhe, Germany). The inclined angle of laminography was also chosen to be $25^{\circ}$. A white X-ray beam in a photon energy window of 9.6-24 keV with the maximum flux density located at $14.5 \mathrm{keV}$ was used. A high speed camera pco.dimax (PCO AG, Germany) combined with continuous sample rotation was employed. The pco.dimax camera had a $2016 \times 2016$ pixels CMOS sensor with $11 \mu \mathrm{m}$ $\times 11 \mu \mathrm{m}$ pixel size. It was coupled to an optical microscope (Optique Peter, France) consisting of a $10 \times$ objective $(\mathrm{NA}=0.28)$ without eyepiece, which resulted in an effective pixel size of $1.1 \mu \mathrm{m}$, and a corresponding FOV of $2.2 \times 2.2 \mathrm{~mm}^{2}$. A $10 \mu \mathrm{m}$ thin LSO crystal (Tb-doped $\mathrm{Lu}_{2} \mathrm{SiO}_{5}$ ) scintillator was chosen to be combined with the optical microscope according to optimization of the depth of focus and scintillator efficiency. Volumes were reconstructed from 2000 angularly equidistant radio- graphs, the exposure time of each projection was $\sim 20 \mathrm{~ms}$, guaranteeing a total scanning time of around $50 \mathrm{~s}$ for a single laminogram. The final reconstructed volumes had a size of $2016 \times$ $2016 \times 2016$ voxels.

The main experimental parameters of the two measurements are summarized in Table 1.

\section{Results}

The polymer matrix is shown in grey, the machined notch is in dark grey, and the voids/cracks are in black, surrounded by white X-ray phase contrast fringes. ${ }^{55}$ Figure 3 a shows the as-received material, it seems that there is no pre-existing cavity in the bulk material. However, it should be mentioned that this conclusion is only valid for voids that can be detected by the pixel resolution limit of $0.75 \mu \mathrm{m}$. In addition, polymers develop crazes that can be considered as cracks the opening of which are bridged with fine fibrils. A craze transforms into a real crack when the fibrils are broken down. Since those nanometric fibrils could not be resolved at the given resolution, it did not allow differentiation between crazes and cracks, therefore all the craze-like features found in the current study will be referred to as cracks. The following discussions will be based on these consideration. 


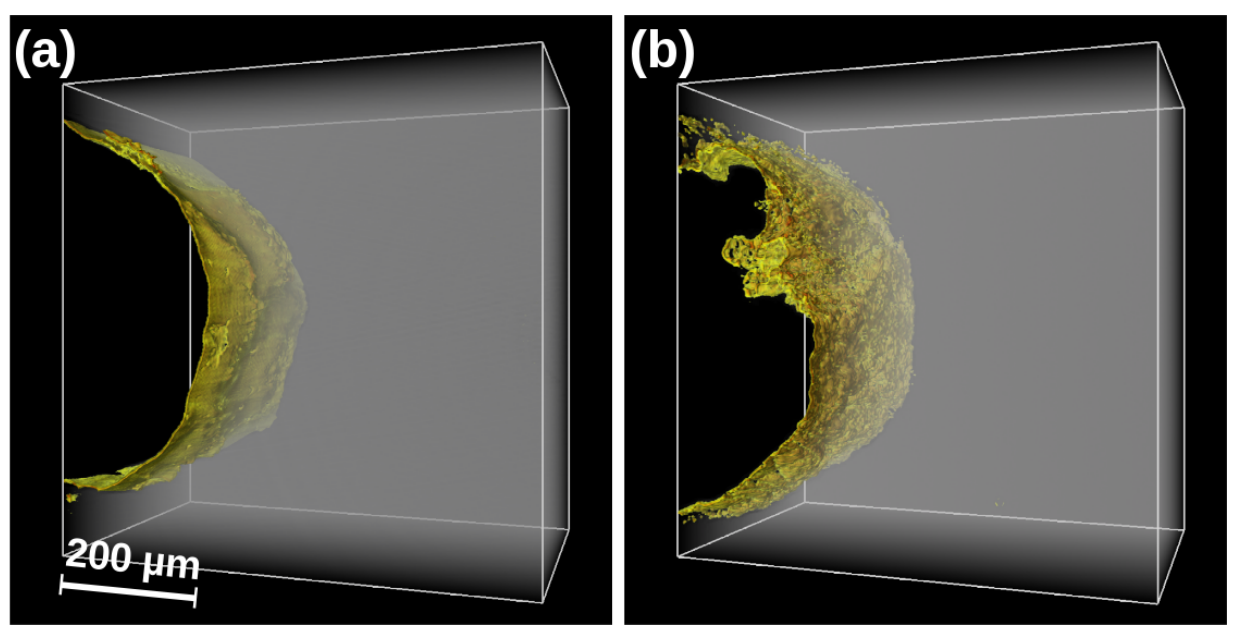

Figure 2: Comparison of the two initial notch surfaces in 3D. (a) defect-free notch, and (b) defective notch. The notch (black), notch curvature (golden), and polymer matrix (grey) are rendered independently.

Table 1: The parameters of two X-ray laminographic imaging experiments

\begin{tabular}{|c|c|c|}
\hline & $\begin{array}{l}\text { Defect-free } \\
\text { notch }\end{array}$ & $\begin{array}{l}\text { Defective } \\
\text { notch }\end{array}$ \\
\hline Synchrotron & ESRF & ANKA \\
\hline Notch machining & $\begin{array}{l}\text { milling } \\
\text { tool cut }\end{array}$ & $\begin{array}{l}\text { rotating } \\
\text { wire saw } \\
\text { cut }\end{array}$ \\
\hline Notch root radius & $0.25 \mathrm{~mm}$ & $0.28 \mathrm{~mm}$ \\
\hline Loading steps & 10 & 12 \\
\hline X-ray energy & $\begin{array}{l}25 \mathrm{keV} \\
\text { monochro- } \\
\text { matic }\end{array}$ & $\begin{array}{l}\text { White- } \\
\text { beam with } \\
15 \quad \mathrm{keV} \\
\text { peak }\end{array}$ \\
\hline Projections & 1500 & 2000 \\
\hline Voxel size & $0.75 \mu \mathrm{m}$ & $1.1 \mu \mathrm{m}$ \\
\hline Detector & $\begin{array}{l}2048 \times 2048 \\
\text { pixels } \\
\text { Frelon }^{58}\end{array}$ & $\begin{array}{l}2016 \times 2016 \\
\text { pixels } \\
\text { CMOS } \\
\text { pco.dimax }\end{array}$ \\
\hline $\mathrm{FOV}$ & $\begin{array}{l}\sim 1.5 \times 1.5 \\
\mathrm{~mm}^{2}\end{array}$ & $\begin{array}{l}\sim 2.2 \times 2.2 \\
\mathrm{~mm}^{2}\end{array}$ \\
\hline Scanning type & $\begin{array}{l}\text { local } \\
\text { laminogra- } \\
\text { phy }\end{array}$ & $\begin{array}{l}\text { full-field } \\
\text { laminogra- } \\
\text { phy }\end{array}$ \\
\hline Exposure time & $50 \mathrm{~ms}$ & $20 \mathrm{~ms}$ \\
\hline Scintillator & $\begin{array}{l}20 \quad \mu \mathrm{m} \\
\text { GGG:Eu } \\
\text { crystal }\end{array}$ & $\begin{array}{l}10 \mu \mathrm{m} \text { thin } \\
\text { LSO:Tb } \\
\text { crystal }\end{array}$ \\
\hline
\end{tabular}

\section{Defect-Free Notch}

2D sections of reconstructed laminography data in the sheet (L-P) plane at the mid-thickness of the sample are presented in Figure 3, showing the damage evolution ahead of the defect-free notch up to a CMOD of $6 \mathrm{~mm}$. Further than that, the notch was missed in the FOV during the X-ray measurement so as we failed to follow the crack propagation any longer (Supporting Information Figure S4). Nevertheless, the observed damage features in this early deformation stage (crack initiation) showed good agreements with the levels of stress states ahead of a notch tip. ${ }^{59}$ That is, a stress gradient is known to exist with higher stresses close to the notch tip and lower stresses at distances further away from the notch. The well distributed damage zones along the notch root axis can be clearly distinguished, as illustrated in Figure $3 \mathrm{c}-\mathrm{d}$. It should be noted that the morphology and the "arrangement" (i.e. in polar fans or tunnel cracks composed of radial coalesced disks) were attributed to different levels of the stress triaxiality ratio $\left(\tau_{\sigma}\right)$ by Laiarinandrasana et $a l:{ }^{60,61}$

Zone 0) A non-damage layer $\sim 33 \mu \mathrm{m}$ in the vicinity of the notch surface, where the stress state is uniaxial $\left(\tau_{\sigma} \sim 1 / 3\right)$. It is consistent with the $\mathrm{SR} \mu \mathrm{CT}$ observations on smooth round bar specimens where a surface layer of $\sim 30 \mu \mathrm{m}$ is also free from 


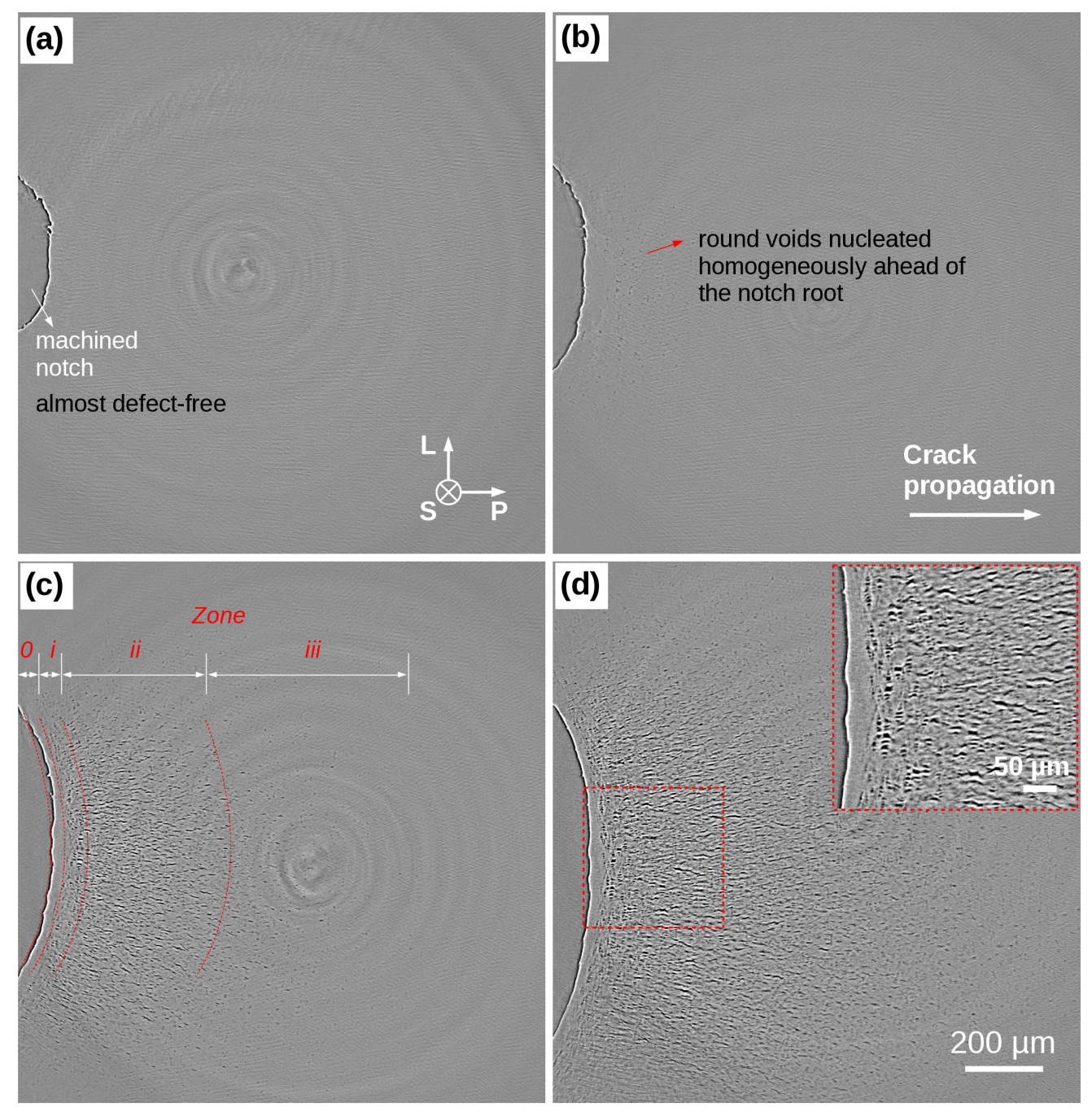

Figure 3: Reconstructed 2D cross-sections (L-P) at the mid-thickness of the PA6 (defect-free notch) sheet plane, showing homogeneously initiating and growing damage features lying in distinct zones which are well associated with stress levels. (a) As-received material; (b) CMOD $=2.5 \mathrm{~mm}$; (c) $\mathrm{CMOD}=4.5 \mathrm{~mm}$; (d) CMOD $=6 \mathrm{~mm}$. The inset is an enlarged view of the red dashed box, zone $0, i, i i$ and $i i i$ are clearly discernible.

damage $;^{27}$

Zone i) Polar fan composed of pile ups of penny shaped cracks arranged as void column like features; the crack surfaces being per-Zone iii) pendicular to the load direction. This domain corresponds to moderate $\tau_{\sigma}$ although $\tau_{\sigma}>1 / 3$. The maximum principal stress is parallel to the load direction so that it is normal to the crack surfaces;

Zone ii) Longer cracks (tunnel crack) with typical length of $30-45 \mu \mathrm{m}$ were piling up parallelly in the loading direction: interor intra-spherulitic cracks prevailed here crossing several spherulites. ${ }^{18,62}$ It is con- sidered that the maximum $\tau_{\sigma}$ as well as the maximum largest principal stress were reached in this area;

Further away from the notch and beyond zone ii, tiny round cavities were observed. In this region, the level of $\tau_{\sigma}$ and the largest principal stress have decreased compared with those of zone ii.

More pronounced damage can be differentiated in different zones in (d) - cracks increase in height during deformation and it is expected that the main crack would take place in the center of the notch root by breaking zone 0 and zone $i$. 

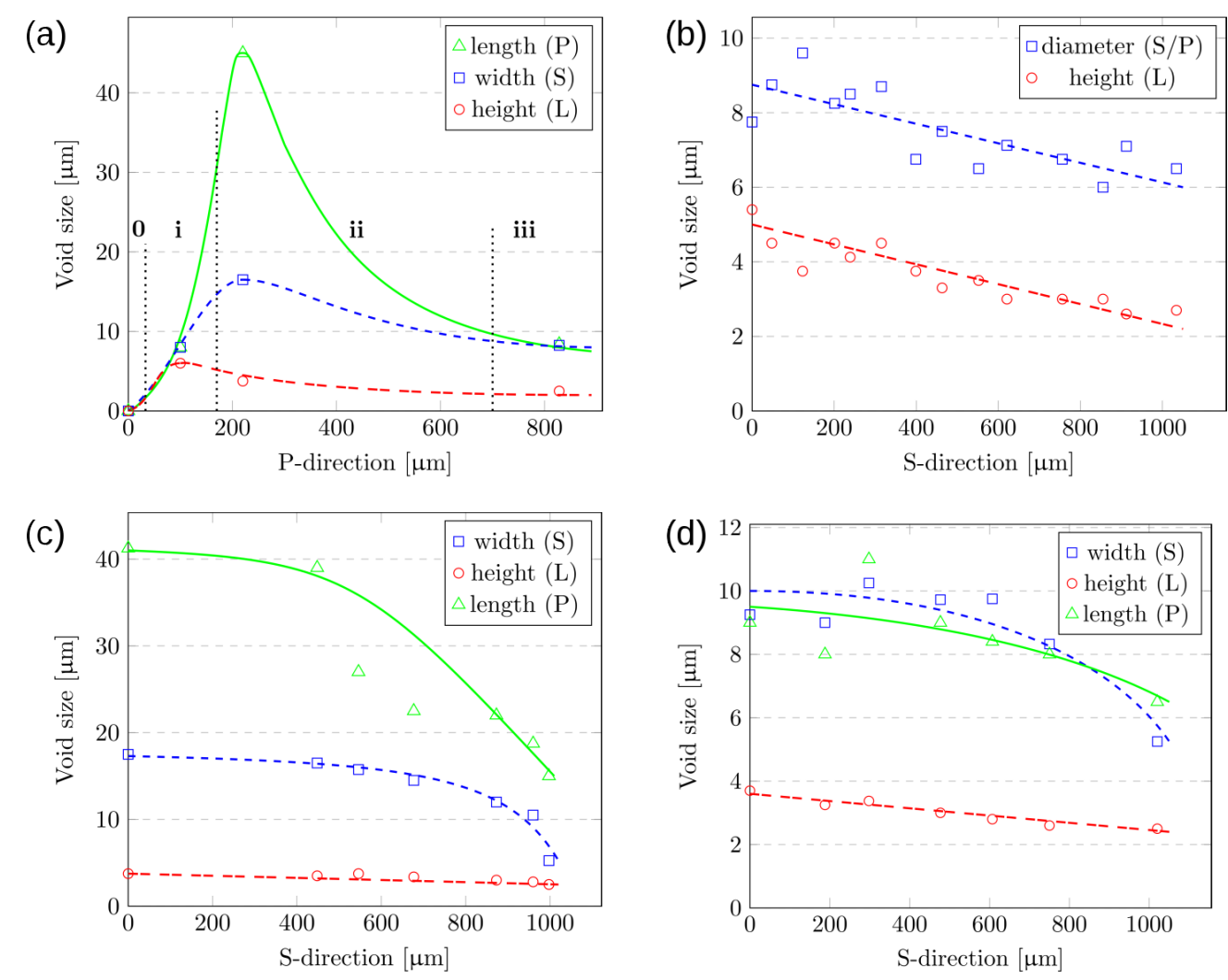

Figure 4: 3D Cavity distribution at $\mathrm{CMOD}=6 \mathrm{~mm}$ of the defect-free notch specimen. (a) cavity dimensions at the mid-thickness along the crack propagation $(\mathrm{P})$ direction; cavity dimensions along the through-thickness (S) direction, from the center to the surface of the specimen at (b) a distance $\sim 54 \mu \mathrm{m}$ ahead of the notch tip (inside zone $i$ ), (c) a distance $\sim 225 \mu \mathrm{m}$ ahead of the notch tip (inside zone $i i$ ), and (d) a distance $\sim 840 \mu \mathrm{m}$ ahead of the notch tip (inside zone iii).

An attempt was made to measure the characteristic lengths of individual voids within the volume corresponding to $\mathrm{CMOD}=6 \mathrm{~mm}$. To this end, the voids were selected at some specific locations related to each zone. The cavity dimensions are denoted as length, width and height corresponding to the directions of $\mathrm{P}, \mathrm{S}$ and L. Figure 4 illustrates the collected data. Around the mid-thickness in the L-P plane, the obtained cavity sizes were plotted along the P-direction starting from the notch tip (zero position, Figure 4a). The damage zones were clearly discerned: the tunnel cracks in zone ii had maximum dimensions in length and width, whilst the polar fan cracks in zone $i$ possessed the maximum height dimension, which were in good agreement with our observation in Figure $3 \mathrm{c}-\mathrm{d}$.

Furthermore, looking at different zones, three distances of about 54, 225 and $840 \mu \mathrm{m}$ ahead of the notch tip were respectively chosen to analyse the cavity size distribution along the thickness (S) direction. In Figure 4b, it can be seen that, within zone $i$, the diameter and height of the polar fan penny shaped cracks decreased from the center to the surface of the specimen. Inside zone ii (Figure 4c), the length and width of the tunnel cracks decreased whilst their heights relatively stayed the same from the core to the surface. Further away from the notch tip in zone iii (Figure 4d), the cavities maintained a similar scale and tendency in length and width dimensions, and their height also did not vary much through the specimen's thickness analogous to the observation in its neighbourhood zone ii. (Note: In Figure 4b$\mathrm{d}$, the undeformed thickness of $2 \mathrm{~mm}$ was used although lateral neckings appeared around the notch roots. Actually, whereas the lateral surface is visible in the volumes, the plane at midthickness could not be precisely located.) 

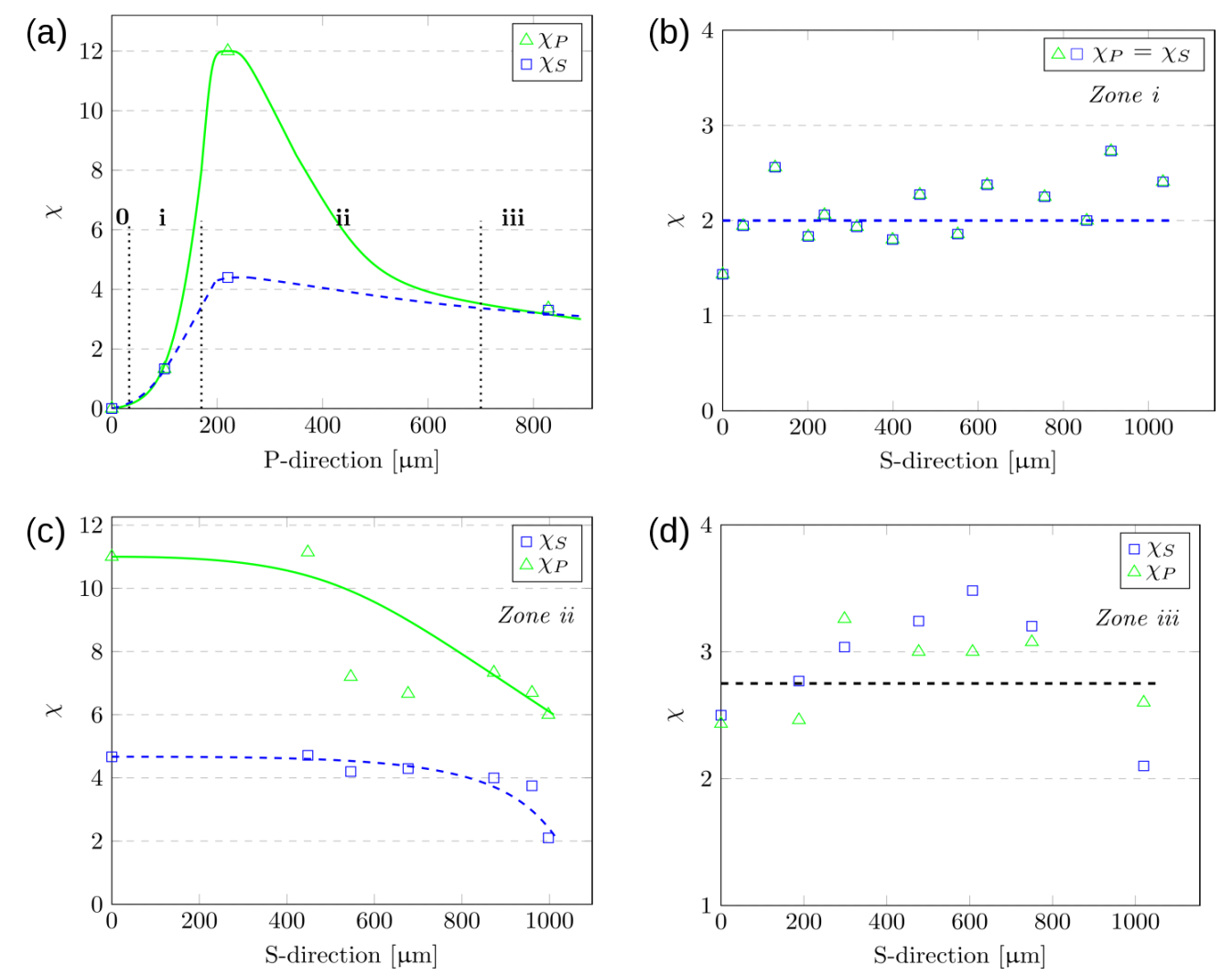

Figure 5: (a) $\chi_{P} \simeq \chi_{S}$ except for zone $i$. (b) and (d): eventually $\chi_{P}=\chi_{S}$ but the value slightly evolves through the thickness. Increasing or decreasing towards the surface depending on the relative decrease of $\mathrm{P} / \mathrm{S}$ and $\mathrm{L}$. (c) corresponding to zone ii shows the only case where $\chi_{P}>\chi_{S}$.

To go further, a concept of void shape factor noted as $\chi$ is introduced as the ratio between the length/width and the height: $\chi_{P}=P / L$ and $\chi_{S}=S / L$. Figure 5 reports the $\chi_{P}, \chi_{S}$ relationship based on the Figure 4 plots. Obviously, for axisymmetrical voids (penny shape, cylinder) $\chi_{P}=\chi_{S}$, which is the case corresponds to zone $i\left(\chi_{P}=\chi_{S}=2\right)$ and zone iii $\left(\chi_{P} \simeq \chi_{S}=2.8\right)$. Whereareas zone $i i$ is the only case where $\chi_{P}>\chi_{S}$ owing to the coalescence of voids in the $\mathrm{P}$ direction in this zone. Therefore the onset of $\chi_{P} / \chi_{S}>1$ can be considered as the criterion for crack initiation. It is also found that the shape factor reaches its maximum value at the mid-thickness and gradually decreases towards the lateral surfaces.

\section{Defective Notch}

The damage evolution in the defective notch specimen in the L-P midplane is shown in Figure 6 corresponding to twelve loading steps. At the initial state, the machined notch with de- fects is seen, with initial voids appearing in the vicinity of the notch surface.

At the first two loading steps (b-c), there was no obvious effect except a slight lateral opening of the notch along the tensile drawing direction. At $\mathrm{CMOD}=0.7 \mathrm{~mm}(\mathrm{~d})$, it is seen that damage started to set in: small cracks initiated, grew and became visible either in the defect area (red arrow) or ahead of the notch somewhere within the material bulk (red ellipse). The latter damage is consistent with the fact that the highest stress triaxiality was located at some distances ahead of the notch surface rather than at the site of the notch. ${ }^{43,48,63}$ At CMOD $=1.05 \mathrm{~mm}$ (e) these cracks have a typical size of $14-19 \mu \mathrm{m}$ and leave a zone free from damage (zone 0 ) with a thickness $\sim 33 \mu \mathrm{m}$ in front of the notch (indicator in Figure 6e). The defect-free zone is consistent with plane stress conditions found. This is also in good agreement with the finding for the defect-free notch specimen reported in Figure 3.

It is worth noting that fairly large cracks (Fig- 

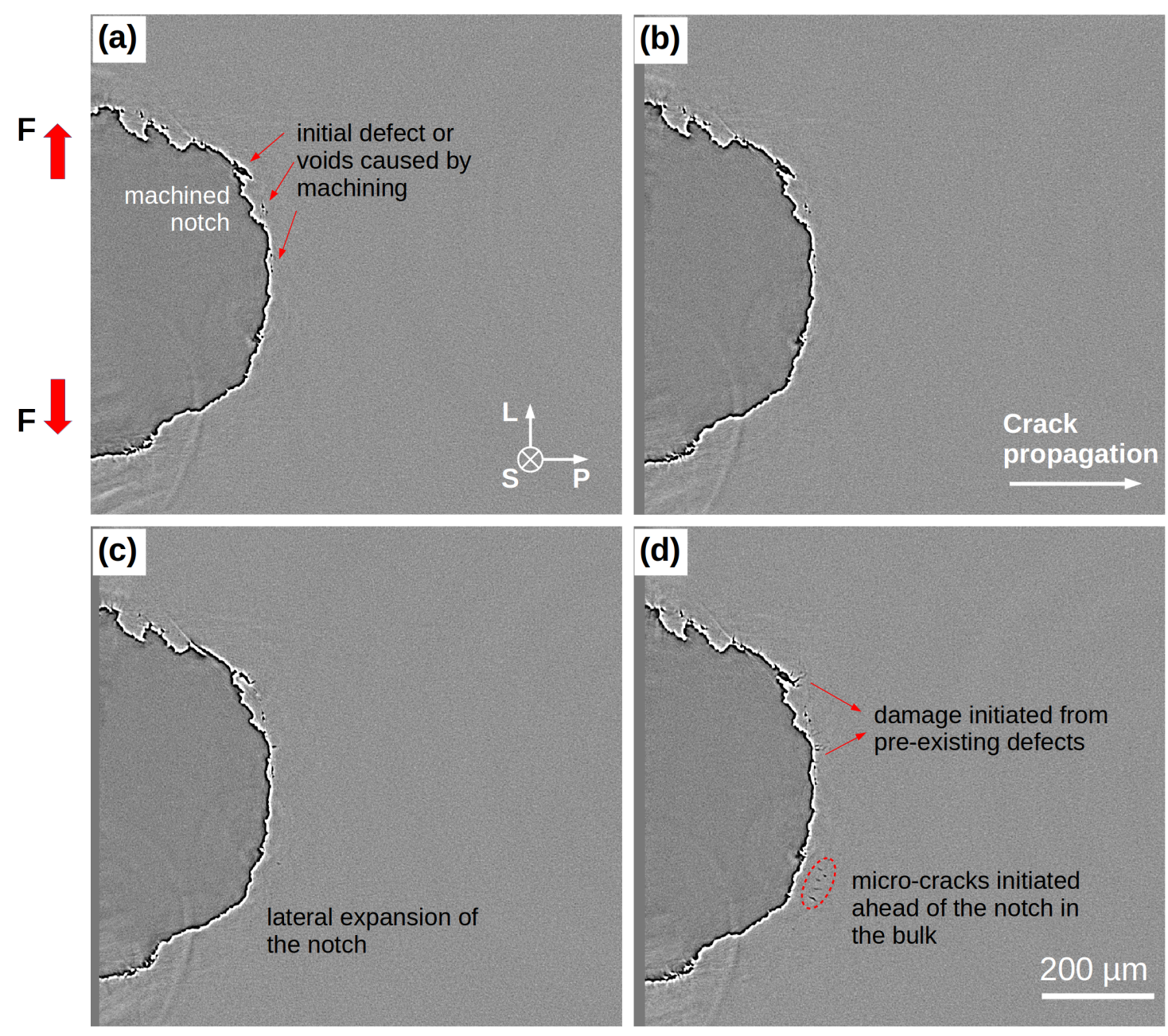

Figure 6: 2D cross-sections (L-P) at the mid-thickness of the PA6 (defective notch) sheet plane of reconstructed laminography data showing crack initiation at incremental CMODs. (a) As-received material; (b) $\mathrm{CMOD}=0.35 \mathrm{~mm}$; (c) CMOD $=0.525 \mathrm{~mm}$; (d) $\mathrm{CMOD}=0.7 \mathrm{~mm}$.

ure 6f, zone ii) are oriented radially with regard to the notch circumference: this can be correlated to the characteristics of craze/crack in semicrystalline polymers: crazes are known to propagate perpendicularly to the maximum principal stress. ${ }^{43,64,65}$ In our case, the principal stress is the tangential component of the tensile force along the notch girth circumference and reaches a maximum value at the mid-thickness, as indicated by the red component in the inset image of Figure $6 \mathrm{f}(\mathrm{CMOD}=1.4 \mathrm{~mm})$. Further away from the notch round voids appear (zone iii). The cracks that started from the notch imperfection (zone ii) are caused by the very locally generated stress concentration.

This concentration leads to amplified damage growth from $\mathrm{CMOD}=2.1 \mathrm{~mm}(\mathrm{~g})$ to $\mathrm{CMOD}=$ $2.8 \mathrm{~mm}(\mathrm{~h})$. The upper part of the notch (zone ii) became the favorable site for damage nucleation, due both to the defect and also attributed to the residual material after notch machining seen previously in 3D in Figure 2, which acts as a stress relief in the central part of the notch and as a stress raiser in the corners of the notch.

As a consequence, apart from this stress intensification zone: at the center of the notch, void columns that aligned parallel to the tensile direction were found (zone i, Figure 6h) consistent with lower stress triaxiality levels. This will be seen below from a 3D rendering in Figure 9 which finely shows their morphology cylindrical in the middle and conical at both ends. The void column can be interpreted as "polar fan" damage in the polar regions of two adjacent spherulites. ${ }^{17,24,25}$ They are typically found for deformations under less severe (mod- 

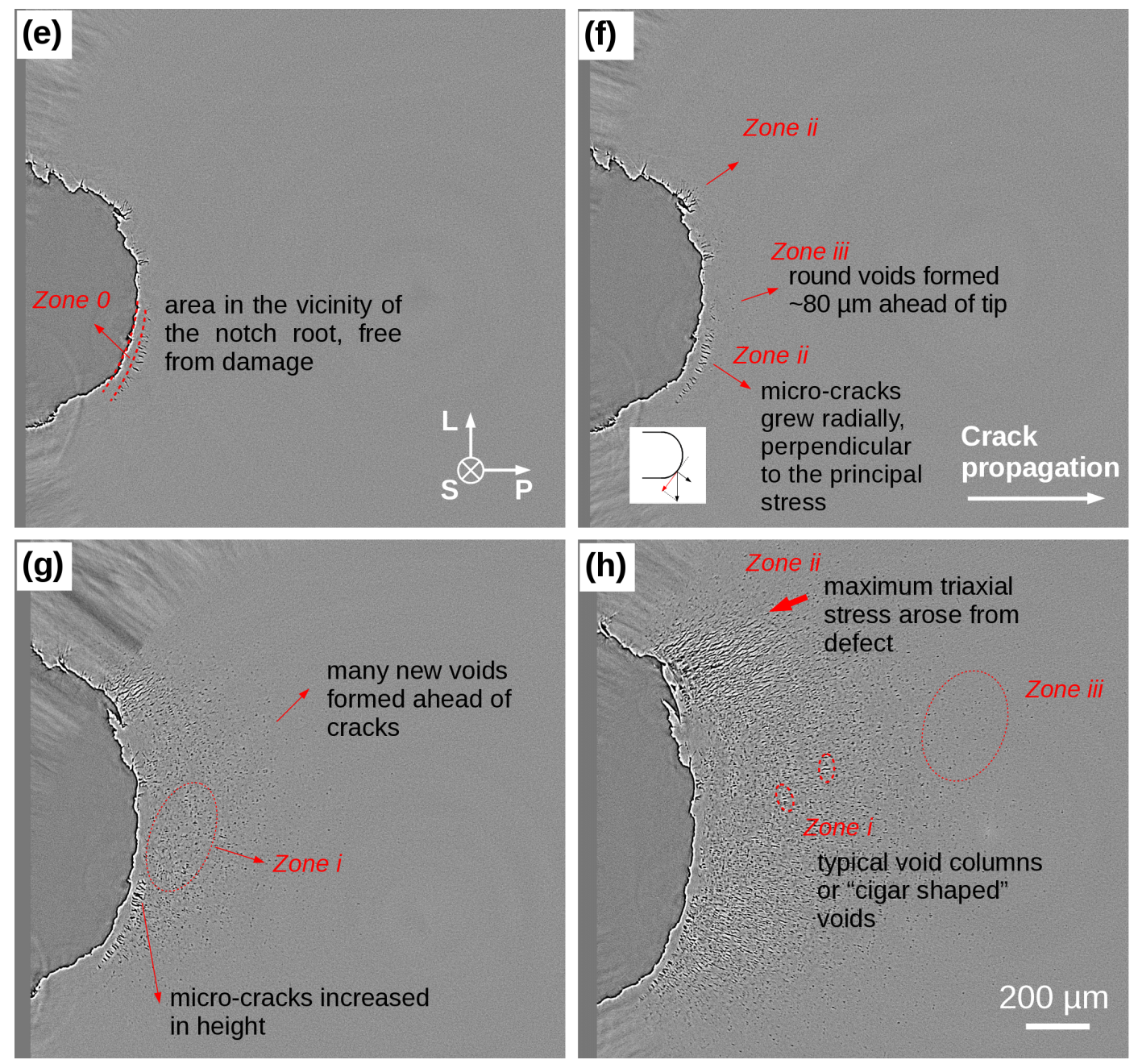

Figure 6: (Continued) 2D cross-sections (L-P) at the mid-thickness of the PA6 (defective notch) sheet plane of reconstructed laminography data showing crack growth at CMODs. (e) CMOD = $1.05 \mathrm{~mm}$; (f) $\mathrm{CMOD}=1.4 \mathrm{~mm}$; (g) $\mathrm{CMOD}=2.1 \mathrm{~mm}$; (h) $\mathrm{CMOD}=2.8 \mathrm{~mm}$.

erate) states of stress. ${ }^{27,28}$ Beside, at the bottom corner of the notch, crack growth got retarded.

At $\mathrm{CMOD}=3.5 \mathrm{~mm}$ (Figure $6 \mathrm{i}$ ), the material ligament in the upper corner of the notch was fractured and coalesced with the micro-cracks in front. At this stage, the main crack initiated. At the same time, several new cracks with typical lengths ranging from $26-43 \mu \mathrm{m}$ originated in front of the main crack. They are much larger than the size of the ones in zone $i$ and much larger than the average spherulite diameter. It appears that the elevated level of stress triaxiality allowed the damage features to overcome spherulite borders such as seen in PP for deformations at low temperatures. ${ }^{18}$ From this moment on, the crack entered the propagation regime, and to the authors' knowledge, it is the first time that the crack propagation mechanisms have been revealed in PA6 in situ.

In the propagation regime, whilst the main crack was progressing by coalescence with the forward micro-cracks, at CMOD $=4.2 \mathrm{~mm}$ (Figure 6j), another big secondary crack (red circle) can be clearly seen to have formed in front of the main crack tip with a length of $\sim 150 \mu \mathrm{m}$ and there is a less damaged ligament (length about $124 \mu \mathrm{m}$ ) between the main crack tip and this big secondary crack. It will be shown below that this big crack is a "tunnel" structured crack but not a penny-shaped crack. Indeed, this crack has its largest dimension in its crack propagation direction and three times less in the perpendicular (L-S) section. The observed crack propagation scenario here is to some extent similar to that of slow crack growth (SCG) mechanisms which have been ob- 
Y. Cheng et al., Macromol. Chem. Phys., 217: 701-715 (2016)
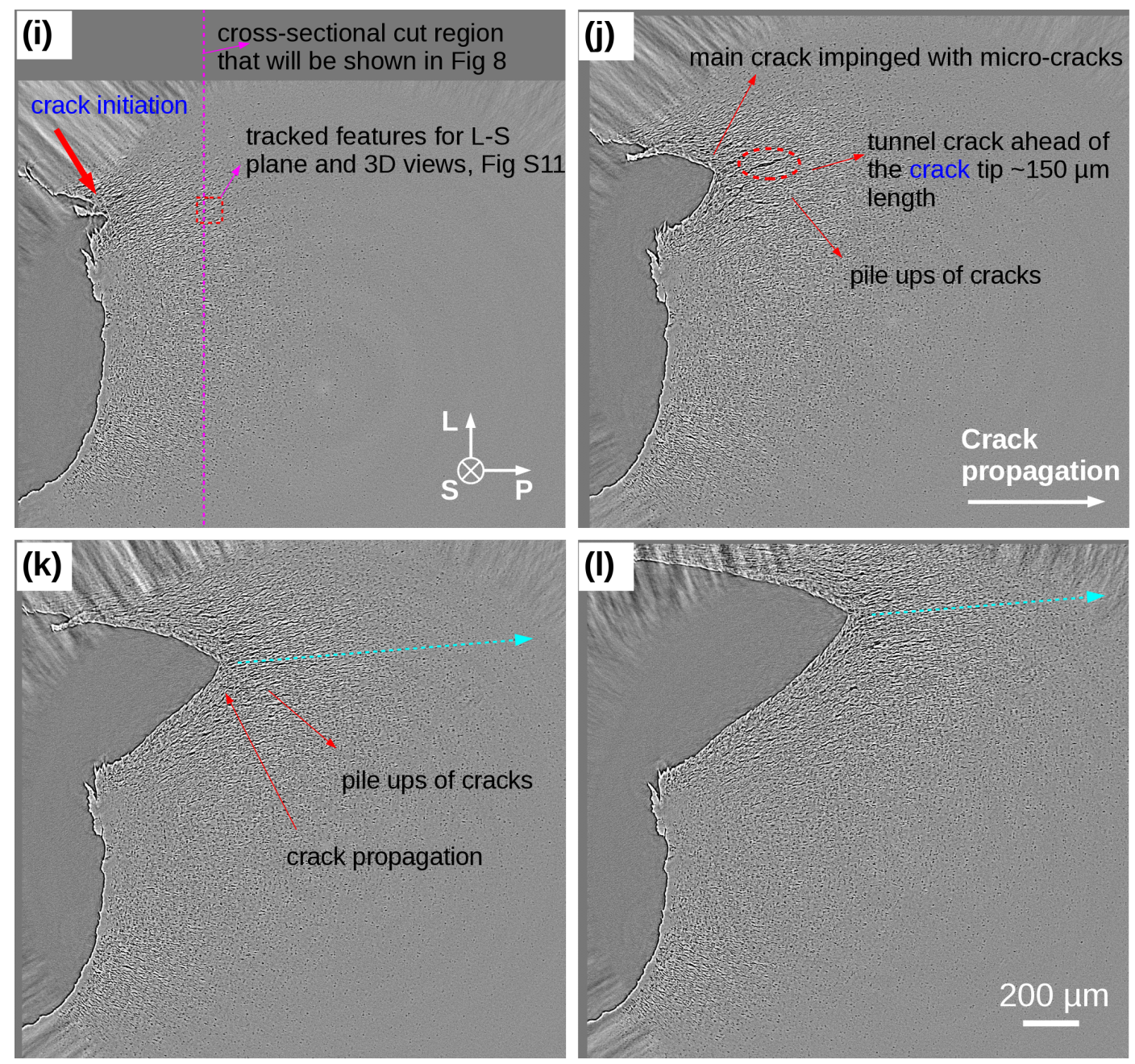

Figure 6: (Continued) 2D cross-sections (L-P) at the mid-thickness of the PA6 (defective notch) sheet plane of reconstructed laminography data showing crack initiation and propagation at CMODs. (i) $\mathrm{CMOD}=3.5 \mathrm{~mm}$; (j) $\mathrm{CMOD}=4.2 \mathrm{~mm}$; (k) $\mathrm{CMOD}=4.9 \mathrm{~mm}$; (l) $\mathrm{CMOD}=$ $5.25 \mathrm{~mm}$.

served in an MDPE under creep condition. ${ }^{66,67}$ However, in creep damage, the zone in front of the secondary craze tip stays undamaged and the crack evolves always into the "virgin" materials. Whereas in our case, damage zones (i.e. crazes, polar fan, round voids) were instantaneously formed ahead of the secondary crack tip causing the main crack always to advance into the damaged materials.

In the next step, at CMOD $=4.9 \mathrm{~mm}$ (Figure $6 \mathrm{k}$ ), the main crack coalesced with the big tunnel crack and to continue propagating. The crack tip progressed by $282 \mu \mathrm{m}$ compared to the last loading stage (j). This value is in agreement with the length of the big crack plus the length of the ligament in $(\mathrm{j})$, which implies that the main crack overcame the remaining ligaments and merged the big secondary crack leading to the crack propagation. New long cracks initiated and grew ahead of the new main crack front, and new round cavities formed further away. These are consistent with the stress states that are similar to the observation in the early stages as well as to the crack initiation in the smooth notch specimen (Figure 3c zone $i$, ii, iii): a stress gradient redistributed ahead of the propagating crack tip. ${ }^{59}$ Moreover, the regions which are not in the crack path, i.e.; above or below the main crack, are unloaded by crack shielding causing a slight closure of the damage features but their overall shape remains similar to the loaded state (Fig. 6k). This means that the elastic relaxation does not dramatically change the void shape. 

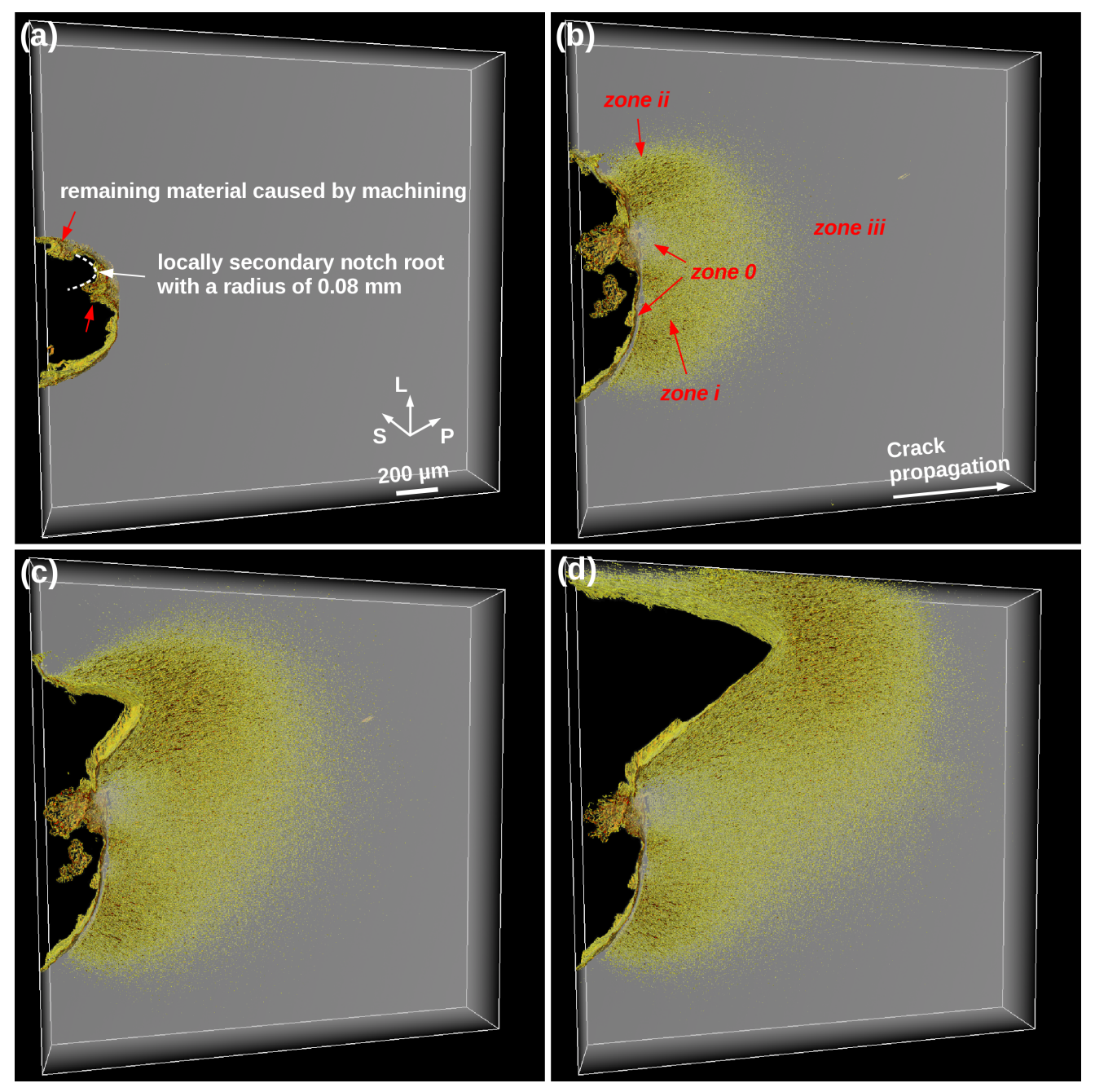

Figure 7: 3D renderings (330 $\mu \mathrm{m}$ thick volume) around the (defective notch) specimen's midplane at different CMODs. (a) CMOD $=0 \mathrm{~mm}$; (b) CMOD $=2.8 \mathrm{~mm}$; (c) CMOD $=4.2 \mathrm{~mm}$; (d) $\mathrm{CMOD}=5.25 \mathrm{~mm}$. The notch is in black, the polymer matrix is shown in grey and the damages are shown varying from light to deep golden depending on the cavitation density of a specific area. Information on the supplementary loading steps is given in video 1 .

From $(\mathrm{k})$ to $\mathrm{CMOD}=5.25 \mathrm{~mm}$ (Figure $6 \mathrm{l})$, since the current crack progression rate is very high, no other intermediate big secondary crack formation between these two steps was observed. The crack runs through the full specimen thickness at (l) (Supporting Information Figure S9g).

SRCL makes it possible to visualize the damage evolution in three dimensions, as shown in Figure 7 , the crack initiation as well as crack propagation are clearly depicted. During deformation, the residual material of the defective notch induced a local secondary notch effect which pronely influenced the stress distribution in front of the notch root. As can be seen in Figure $7 \mathrm{~b}$, the central grey part (zone 0 ) in the vicinity of the remnant was free from damage. However, in the upper corner the residual material caused a local notch radius of $\sim 0.08 \mathrm{~mm}$ highly intensified stress and strain (zone ii), while the lower corner (zone $i$ ) was only moderately deformed. As the crack propagated (Figure 7c-d), new stressdamage sites corresponding to new zone $i$, ii, iii were subsequently reproduced ahead of the main crack tip. The crack tip opening displacement (CTOD) ${ }^{59,68}$ was measured to incubate with the applied CMOD (Supporting Information Table S2). In addition, the local CTOD profile was descending from the interior mid- 
Y. Cheng et al., Macromol. Chem. Phys., 217: 701-715 (2016)

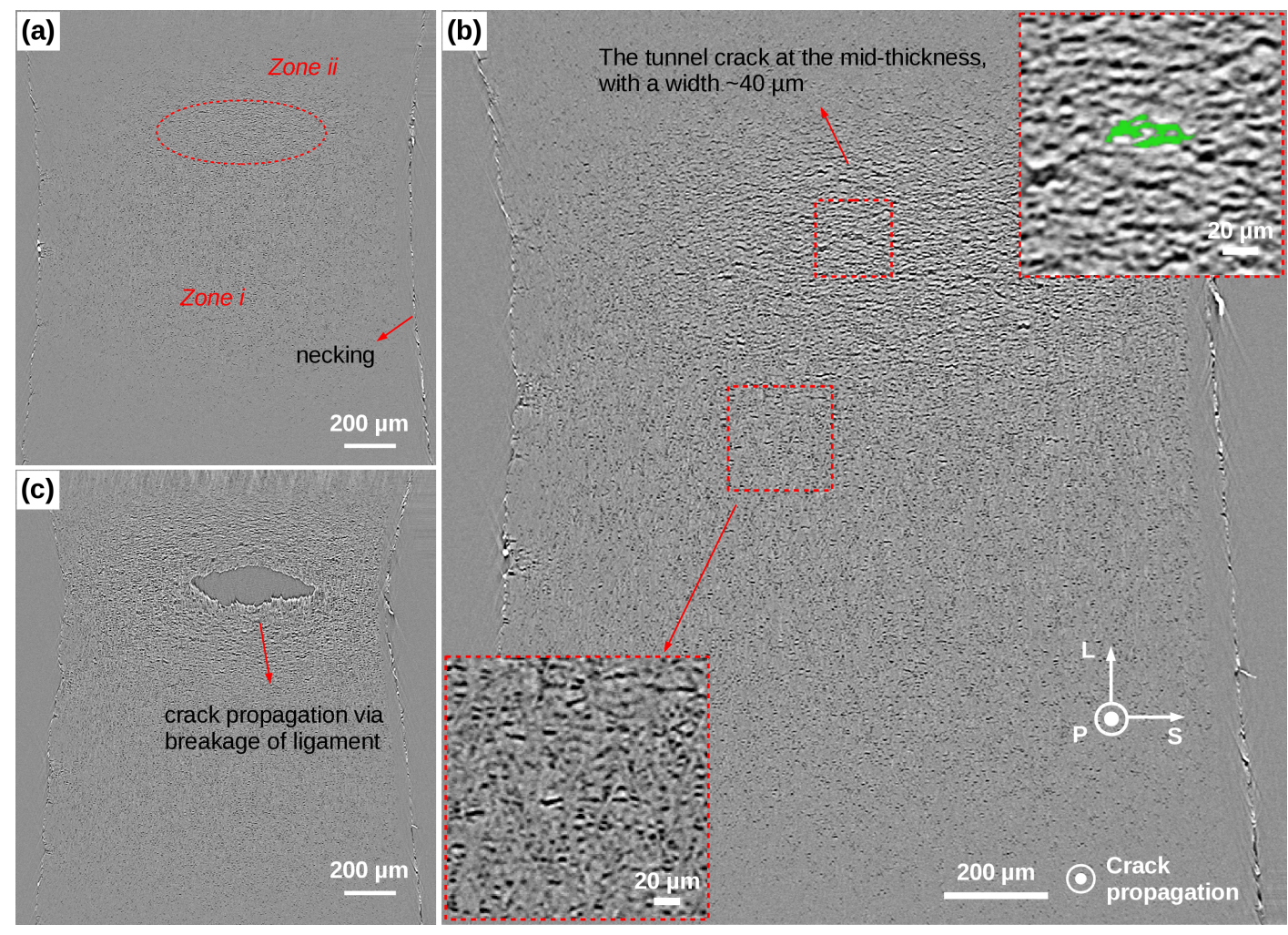

Figure 8: 2D cross-sections at the through-thickness (L-S) plane (through the magenta line indicated in Figure 6i) at a distance of $\sim 350 \mu \mathrm{m}$ from the initial notch shown for different CMODs. (a) $\mathrm{CMOD}=3.5 \mathrm{~mm}$; (b) CMOD $=4.2 \mathrm{~mm}$, the insets are magnified images of the red dashed boxes. The width-height cross-section of the tunnel crack is labeled in green; (c) CMOD $=4.9 \mathrm{~mm}$.

plane to the surface of the specimen (as seen in Figure 9(b)).

To further highlight the microstructure evolution in three dimensions, only voids/cracks in a $(100 \mu \mathrm{m})^{3}$ cubic volume around the midthickness were picked out at different CMODs (location indicated as the red box in Figure 6i). The crack growth and propagation mechanism in terms of void to crazes/cracks transition (i.e., zone iii $\rightarrow$ ii), crack coalescence, and progression are displayed in detail (Supporting Information Figure S11).

In the L-S planes (through-thickness plane), a location $\sim 350 \mu \mathrm{m}$ distant from the initial notch root (indicated by the magenta dashed line in Figure 6i) was chosen to illustrate the damage evolution and mechanism. This plane was chosen with respect to the features indicated in Figure 6i that are tracked for all sections.

At $\mathrm{CMOD}=3.5 \mathrm{~mm}$ (Figure 8a), cracks aligned perpendicular to the loading direction. In addition, most cracks congregated at the middle of the thickness, consistent with the maximum triaxial stress in the center of bulk material. The contrasting densities of cracks in zone $i$ and zone ii arises from the notch defect which is consistent with the L-P observation plane. Necking of the specimen was observed due to deformation.

At $\mathrm{CMOD}=4.2 \mathrm{~mm}$ (b), layers of cracks opened in height and joined together in the loading direction, forming a tunnel-like structure. At this stage, the biggest crack (labelled in green) was still found to be located in the center of the thickness, which was about 40 $\mu \mathrm{m}$ in width and $30 \mu \mathrm{m}$ in height. It is just the same tunnel crack that has already been followed in the L-P plane in Figure 6j. In regions other than the upper part, void columns are the main damage features and may be due to much lower stresses. At CMOD $=4.9 \mathrm{~mm}$ (c), necking was pronounced due to large plastic deformation, the main crack propagated and reached $350 \mu \mathrm{m}$ distance. The cleavage of ligaments and merger of layers of cracks are clearly 

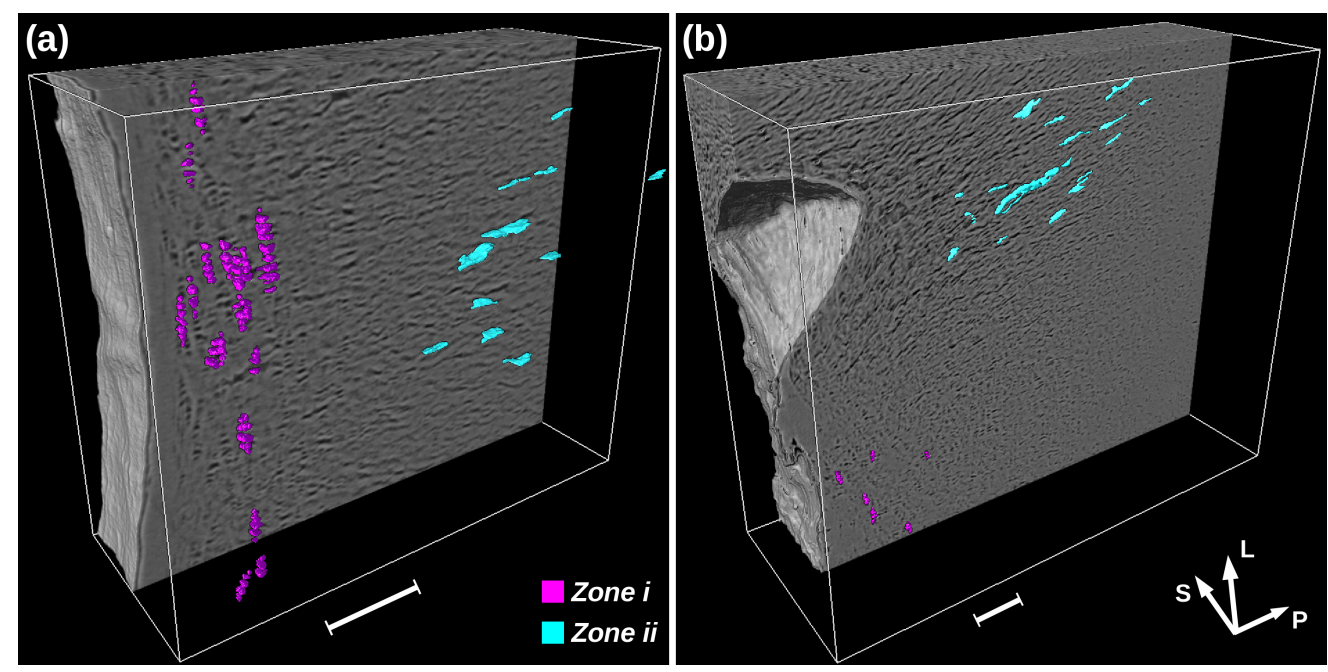

Figure 9: 3D representations of typical damage features in terms of void column in zone $i$ and elongated cracks in zone ii of both (a) defect-free notch at CMOD $=6 \mathrm{~mm}$, and (b) defective notch at $\mathrm{CMOD}=4.2 \mathrm{~mm}$ deformed specimens. The scale bars are $100 \mu \mathrm{m}$. More information in video 2 .

visible from Figure 8b-c.

Two 3D segmented volumes in Figure 9 represent some typical damage features distributed in zone $i$ and zone ii in the bulk material of both specimens. For Figure 9(a) the different 3D shapes of the damage features can be seen: close to the notch root cracks are penny-shaped, and with increasing stress they become tunnelshaped.

\section{Discussion}

Influence of Sample Geometry and Generated Stress State on the Damage Features. Compared to the axisymmetrical specimens observed in tomography, ${ }^{27,28}$ complex damage mechanisms can be seen: The sizes of the cracks that initiated were substantially bigger in diameter. This is indeed an effect of the stresses that: with higher triaxiality and associated normal stress, agglomerated polymer chains, the so-called fibrils may fracture more easily and the large crack may form. These cracks overcame spherulite borders. ${ }^{18,62}$

In the smooth (notch root radius $\mathrm{r}_{0}=\infty$ and at necking $\mathrm{r}_{\text {necking }} \approx 5 \mathrm{~mm}$ ) or notched round bar $\left(\mathrm{r}_{0}=4 \mathrm{~mm}\right)$ specimens, only spherulitic damage that are penny-shaped crazes and polar fan void columns can be observed. ${ }^{27}$ In the smooth round bar specimen, the mean diameter of the central part of the void column is $7 \mu \mathrm{m}$, and $8 \mu \mathrm{m}$ in height (Figure 10a). In the notched round bar $\left(\mathrm{r}_{0}=4 \mathrm{~mm}\right)$ specimen, the maximum damage occurs at the center of the specimen. ${ }^{28}$ The mean diameter of the central part of the void column is $11 \mu \mathrm{m}$, and $8 \mu \mathrm{m}$ in height (Figure $10 \mathrm{~b})$. In the notched round bar $\left(\mathrm{r}_{0}=0.45\right.$ $\mathrm{mm}$ ) specimen, the maximum voiding is located in between the center and the notch root. The increased multiaxial stress state leads to the formation of larger crazes consisting of a cluster of coalesced penny-shaped cracks (Figure 10c) in the net sections of the specimen. ${ }^{69}$ The mean diameter of the cluster is $17.5-35 \mu \mathrm{m}$. The enlargement of those crazes and their transformation to the next morphology are not captured because the stress state is relatively severe and the material fails abruptly after this stage. In the compact-tension like specimens, even higher maximal triaxial stresses are created, in particular a stress gradient is allocated in front of the notch tip. A mixture of specific damage features corresponding to varying levels of stress was observed. The void columns only occurred in the regions with moderate stress triaxiality, and their average size was $9 \mu \mathrm{m}$ (length) by $5 \mu \mathrm{m}$ (height). In these specimens, during crack initiation, long cracks (cluster of coalesced penny-shaped cracks) that were initiated 


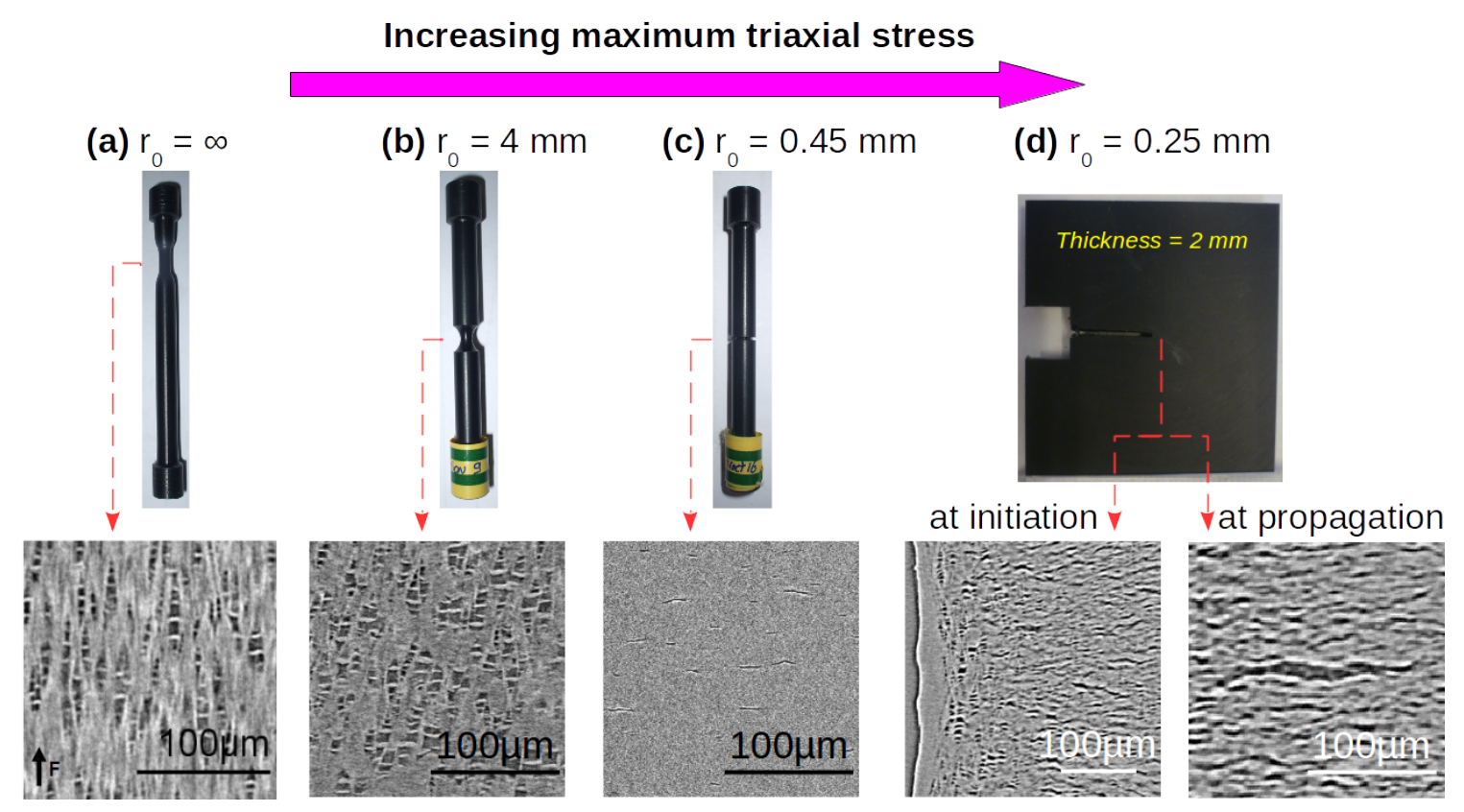

Figure 10: Different specimen geometries that generate different triaxial stress states and corresponding typical associated damage features: (a) Smooth round bar specimen; ${ }^{27}$ (b) Notched round bar specimen with radius $4 \mathrm{~mm} ;{ }^{28}$ (c) Notched round bar specimen with radius $0.45 \mathrm{~mm} ;{ }^{69}$ (d) Compact-tension like specimen with notch radius $0.25 \mathrm{~mm}$.

by severely high stress dominated the failure mechanism, they were of an average length of 30-45 $\mu \mathrm{m}$ and formed at a distance of $\sim 200 \mu \mathrm{m}$ in front of the notch tip. During crack propagation, secondary tunnel cracks (Figure 10d) of $150 \mu \mathrm{m}$ (length) $\times 30 \mu \mathrm{m}$ (height) $\times 40 \mu \mathrm{m}$ (width) formed ahead of the main propagating crack tip.

Tunnel Crack Formation. From previous microstructure assessment of the material (the damage in the round bar specimen was shown to be isotropic in the plane normal to the loading direction ${ }^{28}$ ), the average spherulitic dimensions of materials should be isotropic. The question is why the tunnel crack is anisotropic and not a round penny-shaped crack. Concerning the knowledge of the stress-state ahead of a propagating crack in an elastoplastic material, it is established that there is no strain in crack propagation direction, this implies that there can be stresses in the crack propagation direction. ${ }^{70,71}$ These stresses may lead to the coalescence of small cracks into the tunnel crack. In the through-thickness direction the material necked, which means there was plastic deformation and stresses can be relieved. This is a pos- sible explanation for the fact that the tunnellike crack does hardly propagate laterally.

Slanted Crack Coalescence in Semicrystalline PA6. A hypothetical shear band damage mechanism has been observed in the L$\mathrm{S}$ plane at a distance of $\sim 74 \mu \mathrm{m}$ from the notch root (Figure 11). The slanted cracks were formed between multiple initiated parallelaligned cracks (perpendicular to the loading direction, of an average length $\sim 11 \mu \mathrm{m}$ (equivalent to 2-3 spherulites), they also have a similar spacing around $11 \mu \mathrm{m}$ ), causing a zig-zag cracking path that is likely to undergo a coexistence of inter- and intra-spherulitic fracture course. The slanted cracks intersect at an angle between $50-55^{\circ}$ with respect to the loading direction. As has been documented by various authors, shear banding can exist alongside crazing in many semicrystalline polymers such as HDPE, atactic PS or PP under compression. ${ }^{72-78}$ Although the tests reported in this study were performed under tension, it is noted that the observation of the zone occurs very close to the notch surface. As has been introduced at the beginning, Ferreiro et al. have reported finding fine parallel shear/slip bands 

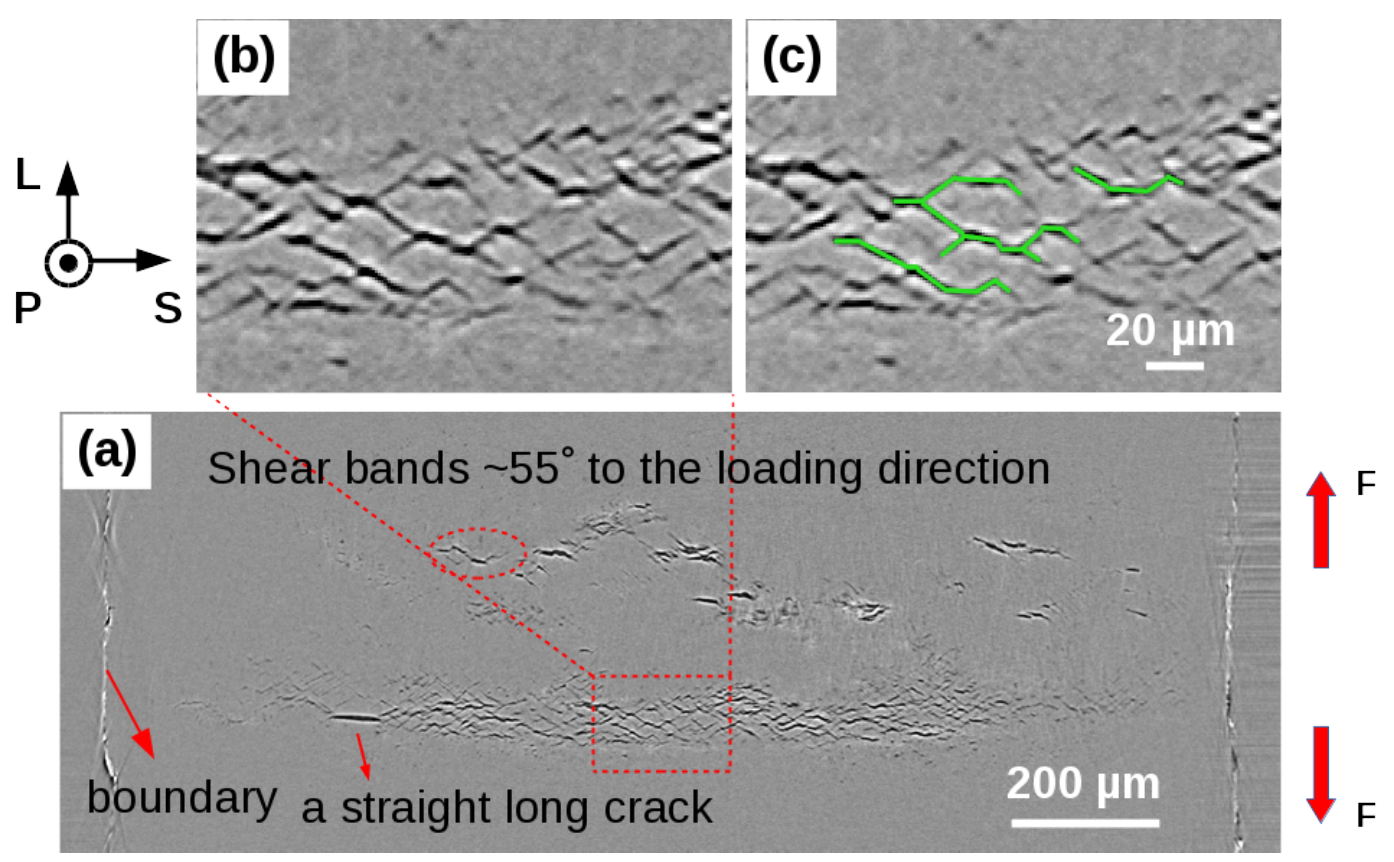

Figure 11: (a) 2D section of reconstructed SRCL data in the through-thickness (L-S) plane at a distance of $\sim 74 \mu \mathrm{m}$ from the initial notch at CMOD $=1.4 \mathrm{~mm}$. (b) Zoomed area of the red dashed box in (a); (c) the highlighted image of (b).

in PA6 which cross the spherulites and run uniformly through the whole sample surface and intersect at $52^{\circ}$ to the direction of the tensile axis. ${ }^{19}$ However the authors also pointed out that the angle deviation from $45^{\circ}$ in their quenched specimen before unloading should not be attributed to a pressure effect due to elastic recovery ${ }^{73,79}$ which actually decreases the angle. The origin for such angles is still unknown. A long straight crack of length $\sim 70 \mu \mathrm{m}$ is also found in this cross-section. A comprehensive depiction of the in situ formation and evolution of these possible shear bands have been supplied in the Supporting Information, Figure S8.

The Impact of Notch Quality on Fracture Toughness. Two qualities of notch have been studied, the defective notch caused early crack progression, and the cracks started both from the notch surface and inside the material. By contrast for the defect-free one, the damage set in later and was not activated directly from the surface. The notch defect prompted very early stress concentration, causing the intermediate damage feature (i.e. void column of zone i) being suppressed, for instance, after the main crack initiated in the defective notch specimen the damage in zone $i$ was almost arrested and remained in height about $2.2 \mu \mathrm{m}$ in the center of the void column (Figure 6i-l, Figure 8b), compared to $4 \mu \mathrm{m}$ height (Figure 3c) while still increasing in the case of the defect-free notch specimen.

\section{Conclusion}

We have achieved the first time in situ observation of micro-damage evolution in a semicrystalline PolyAmide 6 with a severe notch root radius $(0.25 \mathrm{~mm})$ generating high levels of triaxial stresses and also maximum principal stress. Thanks to synchrotron radiation computed laminography $(\mathrm{SR} \mu \mathrm{CL})$ - examination of the crack initiation and propagation in PA6, in a flat $2 \mathrm{~mm}$-thick specimen with a notch, at the micrometer scale in three-dimension was possible. The large flat specimens lead to the formation of plastic zones with large sizes.

In this configuration, the cracks/crazes have larger characteristic diameters than for drawing of initially smooth specimens or specimens with gentler notch root radii. ${ }^{28}$ These crack dimensions are of the order of several average spherulite diameters (average diameter $5 \mu \mathrm{m}$ here). This indicates that higher levels of stress 
triaxiality and maximum principal stress promote the trans-spherulitic failure mechanisms. Damage is to a lesser extent affected by microstructural length scales.

Consistent with the presumed role of maximum stress three main damage zones are found:

0) A damage-free zone $\sim 33 \mu \mathrm{m}$ immediately in the vicinity of the notch surface due to the plain strain state.

i) Short cracks about one spherulite diameter ahead of zone 0 . These cracks grow radially, align perpendicular to the maximum principal stress and increase in height along the loading direction. These cracks are identified as the "polar fan" damage within two adjacent spherulites and display as the void column morphology.

ii) Even longer cracks are initiated ahead of these polar fan damages - these cracks are generally larger than one spherulite diameter (30-45 $\mu \mathrm{m}$ in length), and piling up parallel to the loading direction. This zone sustains the maximum triaxial stress in the bulk material.

iii) Further away, small round cavities were seen to nucleate and be associated with decreasing stress levels compared to zone ii.

Tunnel shaped cracks are formed ahead of the main crack during crack propagation. They are separated from the main crack by a ligament of material that is less damaged. The main crack subsequently coalesces with these tunnel cracks overcoming the ligament of material. The tunnel-like shape of these secondary cracks is consistent with the presumed plane strain conditions, in the propagation direction, of the crack.

During crack propagation, stresses are concentrated in front of the main crack tip; the stress level elsewhere is then partially relieved. New stress zones corresponding to zone $i$, ii, iii are formed and distributed subsequently ahead of the main crack tip. The crack progression is constantly accompanied by stress zone transitions from zone iii (mild stress) to zone $i$ (moderate stress) to zone ii (severe stress) in front of the main crack tip.

In the immediate vicinity of the notch, shear like features were found that have been reported for PA6 thin film in uniaxial tensile loading in the past. ${ }^{19}$ This can be linked to the plane stress state close to the notch surface. This observation highlights the rich information that can be gained in a 3D experiment that screens regions subjected to different stress states.

The impact of notch preparation should be highlighted: The notch prepared by a milling tool showed a smooth surface and damage nucleated away from the notch. In contrast, the specimen with the defective notch made by wire cutting showed a rough surface with remaining material and also initial damage features close to the notch root. For the latter sample crack initiation and propagation occurred at lower strain levels and the location of the damage initiation was shifted to the notch surface. This is consistent with the fact that the defect decreased the effective notch root radius substantially and shifted the maximum principal stress location closer to the notch root. This underlines the importance of notch cutting quality for comparable polymer toughness values testing. Testing using a defective notch will provide conservative lower bound values.

In the present study, the individual spherulite can not be resolved. It would be interesting to synthesize polymers (such as PP) which can possess larger spherulitic sizes in order to map their microstructual 3D damage at the spherulitic level.

Finally, a 3D FE modelling of the experiment would be interesting in order to quantify further the link between maximum principal stresses and the dimensions of the damage features.

Acknowledgement The authors thank ANKA and ESRF for the provision of beamtime MAT-50 and MA-1276, respectively. We thank Harald Schade, Stefan Uhlemann, Tomy dos Santos Rolo, David Haas, Thorsten Müller for their excellent beamline support, and Dr. Martin Köhl for his excellent assistance for 
the use of ANKA GPU computing servers. Dr. Laurent Corté is acknowledged for helpful discussions. Dr. Anthony Bunsell is greatly thanked for proofreading.

\section{Supporting Information Available:} Physicochemical properties of the PA6 under study; the anti-buckling device and the entire in situ loading machine; concise comparison of the principles of CT and CL as well as their respective experimental setups at ANKA and ESRF; results of L-S plane at distances of $13 \mu \mathrm{m}$ and $200 \mu \mathrm{m}$ ahead of the notch tip; video 1 shows the crack initiation and propagation in 3D; video 2 shows distinct damage features and the crack shape in 3D. This material is available free of charge via the Internet at http://pubs.acs.org/.

\section{References}

(1) Peterlin, A. Journal of Materials Science 1971, 6, 490-508.

(2) Kambour, R. P. Journal of Polymer Science: Macromolecular Reviews 1973, 7, $1-154$.

(3) Olf, H. G.; Peterlin, A. Journal of Polymer Science: Polymer Physics Edition 1974, 12, 2209-2251.

(4) Peterlin, A. Polymer Engineering \&3 Science 1977, 17, 183-193.

(5) Peterlin, A. Journal of Applied Physics $1977,48$.

(6) Argon, A. S.; Salama, M. M. Philosophical Magazine 1977, 36, 1217-1234.

(7) Kramer, E. J. In Crazing in Polymers; Kausch, H., Ed.; Advances in Polymer Science; Springer Berlin Heidelberg, 1983; Vol. 52-53; pp 1-56.

(8) Kausch, H. H., Ed. Crazing in Polymers; Advances in Polymer Science; SpringerVerlag: Berlin, 1983; Vol. 52/53.

(9) Kausch, H. H., Ed. Crazing in Polymers Vol. 2; Advances in Polymer Science; Springer-Verlag: Berlin, 1990; Vol. 91/92.
(10) Plummer, C. J. G.; Kausch, H.-H. Journal of Macromolecular Science, Part B 1996, 35, 637-657.

(11) Kausch, H.-H.; Gensler, R.; Grein, C.; Plummer, C. J. G.; Scaramuzzino, P. Journal of Macromolecular Science, Part B 1999, 38, 803-815.

(12) Pawlak, A.; Galeski, A. Macromolecules 2005, 38, 9688-9697.

(13) Pawlak, A.; Galeski, A.; Rozanski, A. Progress in Polymer Science 2014, 39, $921-958$.

(14) Galeski, A.; Argon, A. S.; Cohen, R. E. Macromolecules 1988, 21, 2761-2770.

(15) Aboulfaraj, M.; Ulrich, B.; Dahoun, A.; G'Sell, C. Polymer 1993, 34, 4817 - 4825.

(16) Aboulfaraj, M.; G'Sell, C.; Ulrich, B.; Dahoun, A. Polymer 1995, 36, $731-742$.

(17) Dijkstra, P. T. S.; Van Dijk, D. J.; Huétink, J. Polymer Engineering \&3 Science 2002, 42, 152-160.

(18) Henning, S.; Adhikari, R.; Michler, G. H.; Calleja, F. J. B.; Karger-Kocsis, J. Macromolecular Symposia 2004, 214, 157-172.

(19) Ferreiro, V.; Pennec, Y.; Séguéla, R.; Coulon, G. Polymer 2000, 41, 1561 1569 .

(20) Ferreiro, V.; Depecker, C.; Laureyns, J.; Coulon, G. Polymer 2004, 45, $6013-$ 6026 .

(21) Thomas, C.; Ferreiro, V.; Coulon, G.; Seguela, R. Polymer 2007, 48, 6041 6048.

(22) Thomas, C.; Seguela, R.; Detrez, F.; Miri, V.; Vanmansart, C. Polymer 2009, $50,3714-3723$.

(23) Castagnet, S.; Girault, S.; Gacougnolle, J.; Dang, P. Polymer 2000, 41, 7523 -7530 . 
(24) Pawlak, A.; Galeski, A. Macromolecules 2008, 41, 2839-2851.

(25) Pawlak, A.; Galeski, A. Journal of Polymer Science Part B: Polymer Physics 2010, 48, 1271-1280.

(26) Rozanski, A.; Galeski, A.; Debowska, M. Macromolecules 2011, 44, 20-28.

(27) Laiarinandrasana, L.; Morgeneyer, T. F.; Proudhon, H.; Regrain, C. Journal of Polymer Science Part B: Polymer Physics 2010, 48, 1516-1525.

(28) Laiarinandrasana, L.; Morgeneyer, T. F.; Proudhon, H.; N'guyen, F.; Maire, E. Macromolecules 2012, 45, 4658-4668.

(29) Brusselle-Dupend, N.; Rosenberg, E.; Adrien, J. Materials Science and Engineering: A 2011, 530, 36 - 50 .

(30) Rosenberg, E.; Brusselle-Dupend, N.; Epsztein, T. Materials Science and Engineering: A 2011, 528, 6535 - 6544.

(31) Blaise, A.; Baravian, C.; André, S.; Dillet, J.; Michot, L. J.; Mokso, R. Macromolecules 2010, 43, 8143-8152.

(32) Cherry, B.; Hin, T. S. Polymer 1981, 22, $1610-1612$.

(33) Blaise, A.; Baravian, C.; Dillet, J.; Michot, L.; André, S. Journal of Polymer Science Part B: Polymer Physics 2012, 50, 328-337.

(34) Farge, L.; Andre, S.; Pawlak, A.; Baravian, C.; Irvine, S. C.; Philippe, A.-M. Journal of Polymer Science Part B: Polymer Physics 2013, 51, 826-841.

(35) Morgeneyer, T. F.; Proudhon, H.; Cloetens, P.; Ludwig, W.; Roirand, Q.; Laiarinandrasana, L.; Maire, E. Polymer 2014, 55, $6439-6443$.

(36) Cloetens, P.; Ludwig, W.; Baruchel, J.; van Dyck, D.; van Landuyt, J.; Guigay, J.; Schlenker, M. Appl. Phys. Lett. 1999, 75, 2912.
(37) Cheng, Y.; Suhonen, H.; Helfen, L.; Li, J.; Xu, F.; Grunze, M.; Levkin, P. A.; Baumbach, T. Soft Matter 2014, 10, 2982-2990.

(38) Farge, L.; André, S.; Meneau, F.; Dillet, J.; Cunat, C. Macromolecules 2013, 46, 9659-9668.

(39) Kambour, R. P. Journal of Polymer Science Part A-2: Polymer Physics 1966, 4, $17-24$.

(40) Friedrich, K. In Physik der Duroplaste und anderer Polymerer; Fischer, E., Müller, F., Bonart, R., Eds.; Progress in Colloid \& Polymer Science; Steinkopff, 1978; Vol. 64; pp 103-112.

(41) Friedrich, K. In Anwendungsbezogene physikalische Charakterisierung von Polymeren, insbesondere im festen Zustand; Fischer, E., Müller, F., Bonart, R., Eds.; Progress in Colloid \& Polymer Science; Steinkopff, 1979; Vol. 66; pp 299-309.

(42) Nitta, K.-H.; Takayanagi, M. Journal of Materials Science 2003, 38, 4889-4894.

(43) Zafeiropoulos, N. E.; Davies, R. J.; Roth, S. V.; Burghammer, M.; Schneider, K.; Riekel, C.; Stamm, M. Macromolecular Rapid Communications 2005, 26, 1547-1551.

(44) Narisawa, I. Polymer Engineering \&3 Science 1987, 2\%, 41-45.

(45) Narisawa, I.; Ishikawa, M. In Crazing in Polymers Vol. 2; Kausch, H., Ed.; Advances in Polymer Science, Vol. 91/92; Springer-Verlag, Berlin, 1990; pp 353-391.

(46) Helfen, L.; Baumbach, T.; Mikulík, P.; Kiel, D.; Pernot, P.; Cloetens, P.; Baruchel, J. Appl. Phys. Lett. 2005, 86, 071915 .

(47) Helfen, L.; Baumbach, T.; Cloetens, P.; Baruchel, J. Appl. Phys. Lett. 2009, 94, 104103. 
(48) Morgeneyer, T.; Helfen, L.; Sinclair, I.; Proudhon, H.; Xu, F.; Baumbach, T. Scripta Materialia 2011, 65, 1010 - 1013.

(49) Cheng, Y.; Altapova, V.; Helfen, L.; Xu, F.; dos Santos Rolo, T.; Vagovič, P.; Fiederle, M.; Baumbach, T. Journal of Physics: Conference Series 2013, 463, 012038.

(50) Ramm, A. G.; Katsevich, A. I. The Radon transform and local tomography; CRC press, 1996.

(51) Regrain, C.; Laiarinandrasana, L.; Toillon, S. Engineering Fracture Mechanics 2009, 76, $2656-2665$.

(52) Regrain, C.; Laiarinandrasana, L.; Toillon, S.; Saï, K. International Journal of Plasticity 2009, 25, 1253 - 1279.

(53) Morgeneyer, T.; Helfen, L.; Mubarak, H.; Hild, F. Experimental Mechanics 2013, 53, 543-556.

(54) Weitkamp, T.; Tafforeau, P.; Boller, E.; Cloetens, P.; Valade, J.; Bernard, P.; Peyrin, F.; Ludwig, W.; Helfen, L.; Baruchel, J. AIP Conference Proceedings 2010, 1221.

(55) Cloetens, P.; Pateyron-Salome, M.; Buffiere, J. Y.; Peix, G.; Baruchel, J.; Peyrin, F.; Schlenker, M. Journal of Applied Physics 1997, 81, 5878-5886.

(56) Helfen, L.; Myagotin, A.; Mikulík, P.; Pernot, P.; Voropaev, A.; Elyyan, M.; Di Michiel, M.; Baruchel, J.; Baumbach, T. Rev. Sci. Instrum. 2011, 82, 063702.

(57) Rack, A. et al. Nuclear Instruments and Methods in Physics Research Section B: Beam Interactions with Materials and Atoms 2009, 267, 1978 - 1988.

(58) Falus, P.; Borthwick, M. A.; Mochrie, S. G. J. Review of Scientific Instruments 2004, 75, 4383-4400.
(59) Anderson, T. L. Fracture Mechanics: Fundamentals and Applications, Third Edition; Taylor \& Francis, 2005.

(60) Laiarinandrasana, L.; Lafarge, M.; Hochstetter, G. Fracture mechanics concepts applied to PVDF polymeric material exhibiting porosity, time and temperature dependency. Proceedings of 17th European Conference on Fracture. Brno, Czech Republic, 2008; pp 1562-1569.

(61) Laiarinandrasana, L.; Morgeneyer, T.; Proudhon, H.; Helfen, L. Cavitation in semi-crystalline polymers shown by x-ray tomography: application to constitutive modelling and durability. Proceedings of 16th International Conference on Deformation, Yield and Fracture of Polymers. Rolduc Abbey, Kerkrade, the Netherlands, 2015; pp 35-38.

(62) Schultz, J. M. Polymer Engineering \&3 Science 1984, 24, 770-785.

(63) Tanguy, B.; Besson, J.; Piques, R.; Pineau, A. Engineering Fracture Mechanics 2005, 72, $49-72$.

(64) Strobl, G. The Physics of Polymers: Concepts for Understanding Their Structures and Behavior; Springer, 2007.

(65) Sternstein, S. In Properties of Solid Polymeric Materials, Part B Treatise on Materials Science and Technology; Schultz, J., Ed.; Treatise on Materials Science \& Technology; Elsevier, 1977; Vol. 10, Part B; pp $541-598$.

(66) Hamouda, H.; Simoes-betbeder, M.; Grillon, F.; Blouet, P.; Billon, N.; Piques, R. Polymer 2001, 42, 5425 - 5437.

(67) Hamouda, H. B. H.; Laiarinandrasana, L.; Piques, R. International Journal of Pressure Vessels and Piping 2009, 86, 228 238.

(68) Newman Jr., J. C.; James, M.; Zerbst, U. Engineering Fracture Mechanics 2003, 70, $371-385$. 
(69) Cayzac, H.-A.; Saï, K.; Laiarinandrasana, L. International Journal of Plasticity 2013, 51, $47-64$.

(70) Bron, F.; Besson, J. Engineering Fracture Mechanics 2006, 73, 1531 - 1552.

(71) Buljac, A.; Taillandier-Thomas, T.; Morgeneyer, T.; Helfen, L.; Roux, S.; Hild, F. International Journal of Fracture 2015, $1-14$.

(72) Friedrich, K. In Crazing in Polymers; Kausch, H., Ed.; Advances in Polymer Science, Vol. 52/53; Springer-Verlag, Berlin, 1983; pp 225-274.

(73) Wu, J.; Li, J. Journal of Materials Science 1976, 11, 434-444.

(74) Duckett, R.; Zihlif, A. Journal of Materials Science 1974, 9, 171-173.

(75) Chau, C.; Li, J. Journal of Materials Science 1979, 14, 2172-2182.

(76) Friedrich, K.; Schäfer, K. Journal of Materials Science 1979, 14, 480-483.

(77) Friedrich, K. Journal of Materials Science 1980, 15, 258-262.

(78) Rose, W.; Meurer, C. Journal of Materials Science 1981, 16, 883-888.

(79) Escaig, B. Polymer Engineering \& Science 1997, 37, 1641-1654. 


\section{Graphical TOC Entry}

The in-situ micro-damage mechanisms in semicrystalline PolyAmide 6 are examined in 3D by $\mathrm{X}$-ray imaging for crack initiation and propagation in a large flat specimen. The characteristic sizes of the damage features are quantified. Distinct damage zones are found well distributed ahead of the initial notch, and characterized as a function of stress states. The formation of tunnel cracks during crack propagation and the effect of notch defect are discussed.

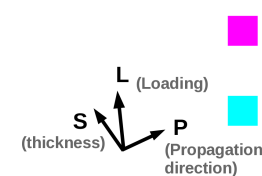

(a) crack initiation

Polar fan damage

(moderate stress triaxiality)

Tunnel crack

(severe stress triaxiality)

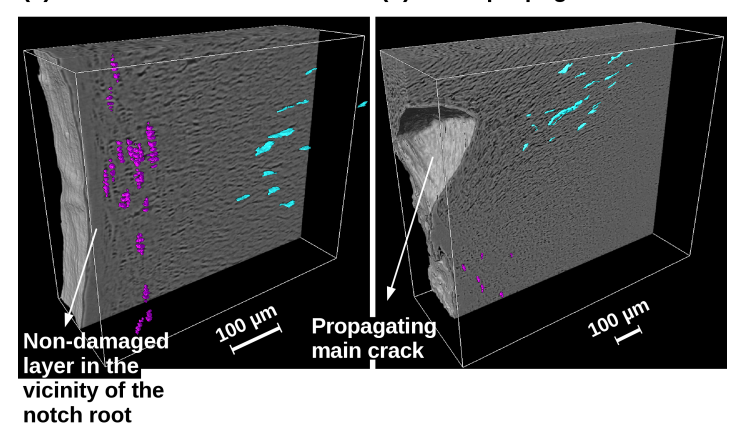

(b) crack propagation 